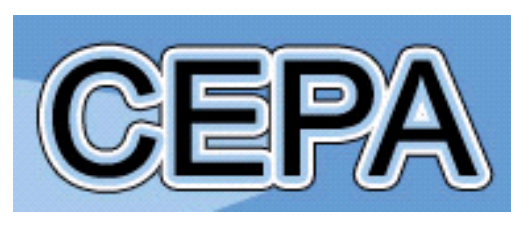

Centre for Efficiency and Productivity Analysis

Working Paper Series

No. WP03/2012

Productivity, Price Recovery, Capacity Constraints and their Financial Consequences

E. Grifell-Tatjé and C. A. K. Lovell

Date:

June 2013

School of Economics

University of Queensland

St. Lucia, Qld. 4072

Australia

ISSN No. 1932 - 4398 


\title{
Productivity, Price Recovery, Capacity Constraints and their Financial Consequences*
}

\author{
E. Grifell-Tatjé \\ Universitat Autònoma de Barcelona \\ C. A. K. Lovell \\ University of Queensland
}

\begin{abstract}
Mining and fishing are both extractive industries, although one resource is renewable and the other is not. Miners and fishers pursue financial objectives, although their objectives may differ. In both industries financial performance is influenced by productivity and prices. Finally, in both industries capacity constraints influence financial performance, perhaps but not necessarily through their impact on productivity, and both industries encounter external as well as internal capacity constraints.

In this study we develop an analytical framework that links all four phenomena. We use return on assets to measure financial performance, and our analytical framework is provided by the duPont triangle. We measure productivity change in two ways, with a theoretical technology-based index and with empirical price-based indexes. We measure price change with empirical quantity-based indexes. We measure internal capacity utilization by relating a pair of output quantity vectors representing actual output and full capacity output, and we develop physical and economic measures of internal capacity utilization. We also show how external capacity constraints can restrict the ability to reach full capacity output. The analytical framework has productivity change, price change and change in capacity utilization influencing change in return on assets.
\end{abstract}

JEL classification: D24

Keywords: duPont triangle, capacity constraints, productivity, price recovery 


\section{Productivity, Price Recovery, Capacity Constraints and their Financial Consequences}

\section{Introduction}

Mining and fishing are both extractive industries, although one resource is renewable and the other is not. Miners and fishers pursue financial objectives, although their objectives may differ. In both industries productivity and prices influence financial performance. In both industries capacity constraints influence financial performance, and both industries encounter external as well as internal capacity constraints, although external capacity constraints have very different sources in the two industries.

We offer two relevant illustrations. First, global mining giant Rio Tinto has generated impressive, albeit volatile, financial results throughout the recent mining boom. Figure 1 depicts five-year moving averages of return on assets and its two drivers, profit margin and asset turnover, from 2008 through $2012 .{ }^{1}$ One would like to learn something about the sources of the observed volatility in return on assets that digs deeper than just variation in the profit margin and asset turnover. Variation in productivity, prices and capacity constraints are likely sources.

\section{Insert Figure 1 About Here}

Second, the Australian Bureau of Agricultural and Resource Economics and Sciences (ABARES) publishes surveys of Australian fisheries that provide detailed boat-level financial information, averaged over boats within fisheries, and similarly detailed economic information for the fisheries themselves, the most recent survey being ABARES (2013). The boat-level financial information includes alternative measures of profit and return on two types of assets. The fishery economic information includes profit and net economic returns, which adjusts profit in several ways, including the incorporation of the costs of managing the fishery. One would like to know something about the sources of variation in profit and return on assets across boats within a fishery, and also about the sources of variation in net economic returns across fisheries and within fisheries through time. Again, variation in productivity, prices and capacity constraints are likely sources.

In this study we develop an analytical framework that links all four phenomena, financial performance, productivity, prices and capacity constraints. We use return on assets ROA to measure financial performance, and the basic analytical framework is the duPont triangle, which decomposes return on assets into the product of a pair of financial ratios, the profit margin and asset turnover. We then develop alternative ways of expressing the two driving financial ratios in terms of 
economic measures of capacity utilization, productivity and price recovery. We measure capacity utilization $\mathrm{CU}$ by relating a pair of output quantity vectors representing actual output and full capacity output, and we use both input-oriented and output-oriented measures of $\mathrm{CU}$. We measure productivity change $\mathrm{Y} / \mathrm{X}$ in two ways, with a theoretical technology-based index and with empirical price-based indexes. We measure price recovery change $P / W$ with empirical quantity-based indexes. The analytical framework has $Y / X, P / W$ and change in $C U$ influencing change in ROA.

The study unfolds as follows. In Section 2 we introduce the duPont triangle as a framework for financial performance evaluation. In Section 3 we incorporate CU into the duPont triangle. In Section 3.1 we follow an input-oriented approach to $\mathrm{CU}$ measurement proposed by Klein (1960) and subsequent writers. In Section 3.2 we follow an output-oriented approach to CU measurement proposed by Gold (1955), Johansen (1968) and subsequent writers. While the components of the duPont triangle and $\mathrm{CU}$ are absolute variables describing levels, $\mathrm{Y} / \mathrm{X}$ and $\mathrm{P} / \mathrm{W}$ are relative variables describing change from one time period to the next. Accordingly, in Section 4 we compare ROA in two time periods by converting the atemporal analytical framework to an inter-temporal one, and we exploit the duPont triangle format to attribute ROA change from one period to the next to CU change, productivity change, and price recovery change. We develop a pair of analytical frameworks, one technology-based and the other price- and quantity-based, within which CU change, productivity change and price recovery change drive ROA change. In Sections 3 and $4 \mathrm{CU}$ is an internal measure associated with short run fixity of some inputs used by the firm. In Section 5 we introduce external capacity constraints originating outside the firm, and we show how these external capacity constraints can render some internal capacity constraints redundant for some firms some of the time. Section 6 concludes.

\section{The duPont Triangle}

ROA is a widely used indicator of financial performance. Bliss (1923), in discussing ROA, claims that "[f]rom the operating point of view as distinguished from the stockholders' point of view, the real measure of the financial return earned by a business is the percentage of operating profits earned on the total capital used in the conduct of such operations... regardless from what sources such capital may have been secured." Two duPont executives, Kline \& Hessler (1952), concur, writing that "It is our considered opinion, which has been critically re-examined many times over three decades, that a manufacturing enterprise with large capital committed to the manufacture and sale of goods can best measure and judge the effectiveness of effort in terms of 'return on investment'." We emphasize that we consider ROA not as a business objective, but a measuring rod of business performance, an observable consequence of the pursuit of a possibly different (indeed, almost any) objective. 
Because ROA is such a popular indicator of financial performance, it has found widespread use in empirical research. It is used as an independent variable in models designed to explain, or predict, executive compensation, default and bankruptcy, and earnings and stock returns. It is a dependent variable in models in which financial performance is hypothesized to be a consequence of human resource management, supply chain management and JIT adoption, the practice of total quality management, corporate social responsibility, corporate environmental performance, and management practices in general. ROA is even in the balanced scorecard, as a component of return on equity.

ROA sits atop the duPont triangle, a management accounting system developed at duPont and General Motors (GM) early in the $20^{\text {th }}$ century. Even then both duPont and GM were diversified corporations, producing a variety of products in several locations, and management had to decide how to allocate capital investment, as well as other resources and managerial compensation, across product lines and among plants. The allocation criterion duPont and GM used was the return earned on those investments. The developers also devised a product pricing formula designed to set product prices that would yield a desired ROA when production was at standard volume, defined at GM to be two shifts per day.

To assist in the resource allocation and product pricing strategies, $\mathrm{ROA}=\pi / \mathrm{A}$ was decomposed into a pair of financial ratios that drive $\pi / A, \pi$ and $A$ being profit and assets, respectively. This in turn enabled management to develop strategies intended to enhance either ratio, and hence $\pi / \mathrm{A}$. The decomposition states that $\pi / \mathrm{A}$ is the product of the profit margin $\pi / R$, and asset turnover R/A, R being revenue. $\pi / R$ indicates how much of sales revenue a firm retains as profit rather than absorbs as expense. An increase in $\pi / R$ is consistent with an improvement in cost efficiency, the adoption of cost-saving technology, a reduction in input prices or an increase in output prices. R/A indicates the revenue productivity of a firm's assets. An increase in R/A is consistent with capital being allocated to higher-valued uses, or an increase in output prices. ${ }^{2}$

For our purposes it is important to note that the duPont triangle contains two financial ratios that drive a third. It does not contain economic measures of $C U$, productivity or price recovert, any one of which is a potential driver of $\pi / R$ or R/A. We incorporate $\mathrm{CU}$ into an atemporal duPont triangle in Section 3, and we incorporate $\mathrm{CU}$ change, along with $\mathrm{Y} / \mathrm{X}$ and $\mathrm{P} /$, into an inter-temporal ratio of duPont triangles in Section 4.

\section{Capacity Utilization}

Incorporating $\mathrm{CU}$ into a duPont triangle requires a definition of capacity, and there are several to choose from. A generic approach is to write the triangle as 


$$
\begin{aligned}
\pi / A & =\pi / R \times R / A \\
& =\pi / R \times p^{\top} y / p^{\top} y^{c} \times p^{\top} y^{c} / A,
\end{aligned}
$$

with output price vector $\mathrm{p} \in \mathrm{R}_{++}^{\mathrm{M}}$, output quantity vector $\mathrm{y} \in \mathrm{R}_{+}^{\mathrm{M}}$, capacity output quantity vector $y^{c} \in R_{+}^{M}$ and capacity utilization measure $C U=p^{\top} y / p^{\top} y^{c}$. The two financial ratios $\pi / R$ and R/A in the first equality are the conventional drivers of ROA. The capacity utilization term in the second equality relates $y$ to $y^{c}$ by means of $p^{\top} y / p^{\top} y^{c}$ and adjusts R/A accordingly. Weighting $y$ and $y^{c}$ by $p$ maintains the financial structure of the triangle and, more significantly for our purposes, allows for multiple outputs in the measurement of the rate of capacity utilization, thus solving a problem that has bedeviled, or escaped, many writers. The second equality in expression (1) decomposes ROA into the product of three drivers: the profit margin, the rate of capacity utilization, and potential asset turnover, the turnover that would occur at full capacity output $\mathrm{y}^{\mathrm{c}}$.

We consider how to define two important variables, ROA and $y^{c}$. ROA is a generic term, with many definitions, all with monetary numerator drawn from the profit and loss statement and monetary denominator drawn from the balance sheet. Perhaps the most common definition is the ratio of earnings before interest expense and taxes (EBIT) to the value of total (fixed and current) assets. ${ }^{3}$

We next consider how to define $y^{c}$, another generic term. Management at GM implicitly defined capacity output as standard volume, the output that could be produced by operating two shifts per day, even though three shifts are technically feasible. Johnson (1978) argued that GM was concerned that operating more than two shifts would be less profitable than operating two shifts, making GM's definition of capacity output a managerial, rather than an engineering, concept. We revisit the distinction in Sections 3.1 and 3.2. We also consider the orientation of a capacity utilization measure. In the duPont triangle the profit margin is expressed as the ratio of profit to revenue. Consequently the capacity utilization component $p^{\top} y / p^{\top} y^{c}$ in expression (1) appears to be output-oriented as well. However, although the duPont triangle is clearly output-oriented, its capacity utilization component is independent of orientation, even though it uses output prices to aggregate multiple outputs and so to compare output quantity vectors $y$ and $\mathrm{y}^{\mathrm{c}}$. Consequently we are free to adopt either orientation when deriving a measure of capacity utilization to be used in expression (1). We explore input-oriented definitions of $y^{c}$ in Section 3.1, and output-oriented definitions of $y^{c}$ in Section 3.2.

\subsection{Input-oriented Capacity Utilization Measures}

"From an economist's viewpoint capacity is a cost concept," wrote Hickman (1964), who defined capacity as that output that minimizes short run average cost, "... given the existing physical plant and organization of production and the prevailing 
factor prices." For clarity we write the input quantity vector $x \in R_{+}^{N}$ and the input price vector $w \in R_{++}^{N}$, and we write $x=\left(x_{v}, x_{f}\right)$ and $w=\left(w_{v}, w_{f}\right), x_{v}$ and $w_{v}$ being variable input quantity and price sub-vectors, and $x_{f}$ and $w_{f}$ being quantity and price subvectors of inputs that are fixed in the short run. This enables us to define a long run cost frontier as $c(y, w)=\min _{x}\left\{w^{\top} x:(x, y) \in T\right\}$ and a short run variable cost frontier as $c_{v}\left(y, w_{v}, x_{f}\right)=\min _{x_{v}}\left\{w_{v}{ }^{\top} x_{v}:\left(x_{v}, x_{f}, y\right) \in T\right\}, T$ being the set of technologically feasible input-output combinations.

Hickman noted that $\mathrm{CU} \gtreqless 1$, and that $\mathrm{CU} \neq 1$ drives short run average cost above minimum because $x_{v}$ "...is either too large or too small to make optimum use of the physical facilities." Hickman's definition of capacity output is consistent with that of Klein, although Klein offered a different defense of the association of capacity output with the rate of output that minimizes short run average cost. For Klein this definition of capacity output is consistent with a zero profit competitive economy.

Other input-oriented definitions of capacity and its rate of utilization have been proposed, all conditioned on $\left(\mathrm{W}_{\mathrm{v}}, \mathrm{x}_{\mathrm{f}}, \mathrm{W}_{\mathrm{f}}\right)$. Figure 2 contains a conventional $\cup$ - shaped long run average cost frontier $\operatorname{LAC}(y, w)$ together with one of its $U$ - shaped short run average cost frontiers $\operatorname{SAC}\left(y, w_{v}, x_{f}, w_{f}\right)=S_{A C}\left(y, w_{v}, x_{f}\right)+w_{f}^{\top} x_{f}$ and its short run marginal cost frontier $\operatorname{SMC}\left(y, w_{v}, x_{f}\right)$. All writers mentioned above and below assume, explicitly or implicitly, that $M=1$ and that the firm is cost-efficient, and for the moment we retain these two assumptions.

\section{Insert Figure 2 About Here}

Figure 2 depicts four input-oriented definitions of capacity output. Output $y^{c 1}$ has been attributed to Klein, who did not propose it. ${ }^{4}$ However it can be recommended on the grounds that it equates short run and long run average (and so total) cost frontiers; for any other output $\mathrm{y} \neq \mathrm{y}^{\mathrm{c} 1}, \mathrm{SAC}\left(\mathrm{y}^{\mathrm{c} 1}, \mathrm{w}_{\mathrm{v}}, \mathrm{x}_{\mathrm{f}}, \mathrm{w}_{\mathrm{f}}\right)>\operatorname{LAC}\left(\mathrm{y}^{\mathrm{c} 1}, \mathrm{w}\right)$. Output $y^{c 2}$ has been recommended by Klein, Hickman and Berndt \& Morrison (1981), among others, on the grounds that it minimizes $\operatorname{SAC}\left(y, w_{v}, x_{f}, w_{f}\right)$; for any other output $y \neq y^{c 2}, \operatorname{SAC}\left(y, w_{v}, x_{f}, w_{f}\right)>\operatorname{SAC}\left(y^{c 2}, w_{v}, x_{f}, w_{f}\right)$. Output $y^{c 3}$ has been recommended on the grounds that it maximizes short run variable profit; any $\mathrm{y} \neq \mathrm{y}^{\mathrm{c} 3}$ would sacrifice profit. Our favorite capacity output vector is $\mathrm{y}^{\mathrm{c4}}$, recommended by de Leeuw (1962); at $y^{c 4}$ short run marginal cost exceeds minimum short run average cost by an arbitrary percent, "... and we would therefore expect a high rate of capacity utilization to represent appreciable upward price pressure and a high level of investment demand." de Leeuw goes on to discuss, and defend, the arbitrariness of the percent. Our candidate for the percent would be the most appropriate producer price index, in which case $\mathrm{y}^{\mathrm{c4}}$ would equate $\operatorname{SMC}\left(\mathrm{y}, \mathrm{w}_{\mathrm{v}}, \mathrm{x}_{\mathrm{f}}\right)$ with the producer price index. 
Writers have generally noted that these alternative definitions of $y^{c}$ are conditioned on the assumption of normal operating conditions. Thus Smithies (1957) writes "[b]y full capacity output I mean the output that the existing stock of equipment is intended to produce under normal working conditions with respect to hours of work, number of shifts, and so forth," a view repeated by de Leeuw, Hickman and others.

We return to the two assumptions. Suppose first that $w^{\top} x>c(y, w)$ or that $w_{v}{ }^{\top} x_{v}>c_{v}\left(y, w_{v}, x_{f}\right)$, i.e. the firm fails to solve the two optimization problems above and allocates $x$ inefficiently in the long run or allocates $x_{v}$ inefficiently the short run. It is straightforward to eliminate cost inefficiency before embarking on the $\mathrm{CU}$ exercise by replacing $w^{\top} x>c(y, w)$ with $w^{\top} x^{C E}=c(y, w)$ and $w_{v}{ }^{\top} x_{v}>c_{v}\left(y, w_{v}, x_{f}\right)$ with $w_{v}{ }^{\top} x_{v}{ }^{C E}=$ $c_{v}\left(y, w_{v}, x_{f}\right), x^{C E}$ and $x_{v}{ }^{C E}$ being cost-efficient input quantity vectors. As for the $M=1$ assumption, in an aggregate environment considered by the writers above "output" is the value of a real output quantity index. At the firm level the problem caused by $M>$ 1 is not the measurement of capacity utilization, but rather the definition of "average" cost from which capacity vectors $y^{c 1}-y^{c 4}$ are derived. We define a long run average cost frontier as $\operatorname{LAC}(\mathrm{y}, \mathrm{w})=\mathrm{c}(\mathrm{y}, \mathrm{w}) / \mathrm{Y}$ and a short run average cost frontier as $\operatorname{SAC}\left(y, w_{v}, x_{f}, w_{f}\right)=\left[c_{v}\left(y, w_{v}, x_{f}\right)+w_{f}^{\top} x_{f}\right] / Y$ respectively, and we define $Y$ as in the aggregate context, as the value of a real output quantity index. In both cases "average" cost incorporates both y and $\mathrm{Y}$, with $\mathrm{Y}=1$ in the base period. ${ }^{5}$

Any of these four input-oriented capacity output vectors can be inserted into the preliminary decomposition of ROA in the second equality in expression (1) to generate capacity utilization measures $C U^{c i}=p^{\top} y / p^{\top} y^{c i}, i=1, \ldots, 4$, with corresponding interpretations of potential asset turnover.

\subsection{Output-oriented Capacity Utilization Measures}

Our analytical framework shifts from cost frontiers to production frontiers. Figure 3 supports three output-oriented definitions of capacity output and its rate of utilization. We observe output vector $y$ and input vector $x$, with $y \in Q(x)$ and feasible set $\mathrm{Q}(\mathrm{x})$ bounded above by its frontier $\mathrm{Q}^{\mathrm{F}}(\mathrm{x}) \subset \mathrm{Q}(\mathrm{x})$. All $\mathrm{y} \in \mathrm{Q}^{\mathrm{F}}(\mathrm{x})$ are maximum output vectors that can be produced by $x$ and given technology. The technically efficient output vector associated with $y$ is $y^{a}=y / D_{0}(x, y) \in Q^{F}(x)$, with $D_{0}(x, y)$ an output distance function defined as $D_{0}(x, y)=\min \{\lambda: y / \lambda \in Q(x)\}$, and the technical efficiency of $y$ is $y / y^{a}=D_{0}(x, y) \leq 1$. As in Section 3.1 we partition $x$ into fixed and variable sub-vectors, so that $x=\left(x_{v}, x_{f}\right)$. This partitioning highlights the fact that capacity utilization is a short-run phenomenon resulting from the inability to expand or contract a sub-vector of inputs in response to increasing or declining demand. Following Gold and Johansen, we define $\mathrm{Q}\left(\mathrm{x}_{\mathrm{f}}\right)$ as the set of feasible output vectors obtainable from $x_{f}$ when no constraints are imposed on the availability and use of $x_{v}$. $\mathrm{Q}\left(\mathrm{x}_{\mathrm{f}}\right)$ is bounded above by its frontier $\mathrm{Q}^{\mathrm{F}}\left(\mathrm{x}_{\mathrm{f}}\right) \subset \mathrm{Q}\left(\mathrm{x}_{\mathrm{f}}\right)$, and all $\mathrm{y} \in \mathrm{Q}^{\mathrm{F}}\left(\mathrm{x}_{\mathrm{f}}\right)$ are full capacity output vectors, given $x_{f}$ and technology. 
Consistent with the writers in the input-oriented Section 3.1, Gold and Johansen gave their definitions of capacity output a managerial slant akin to the use of standard volume at GM. Thus Gold emphasized "practically sustainable capacity," determined by "the customary number of shifts and the normally acceptable length of work day and work week," and with allowance made for breakdowns, repairs and maintenance. Johansen conditioned his definition on the assumption that the firm is "operating under normal conditions with respect to number of shifts, hours of work etc."

\section{Insert Figure 3 About Here}

Our first output-oriented definition of capacity utilization follows Gold and Johansen, and solves a radial output maximization problem. It is independent of prices, and defines capacity output as the largest feasible radial expansion of $y$. In Figure $3 y^{G J}=y / D_{0}\left(x_{f}, y\right) \in Q^{F}\left(x_{f}\right)$ is the full capacity output vector associated with actual output vector $y$, with $D_{0}\left(x_{f}, y\right)=\min \left\{\lambda: y / \lambda \in Q\left(x_{f}\right)\right\}$, and so the rate of capacity utilization is $C U^{G J}=y / y^{G J}=D_{0}\left(x_{f}, y\right) \leq 1$. The superscript "GJ" honors the two pioneers, Gold and Johansen. $\mathrm{CU}^{\mathrm{GJ}}$ is measured holding the output mix constant, and so is useful in the absence of output price information when $M>1$. $C U^{G J}$ is $a$ gross measure of capacity utilization that can be decomposed into the product of an output-oriented technical efficiency term $y / y^{a}=D_{0}(x, y) \leq 1$ and a net capacity utilization term $y^{a} / y^{G J}=D_{0}\left(x_{f}, y\right) / D_{0}(x, y) \leq 1$. We refer to the two components of $C U^{G J}$ as wasted capacity and excess capacity, respectively. ${ }^{6}$

Our second definition follows Segerson \& Squires (1995) and Lindebo et al. (2007), and solves a revenue maximization problem. Segerson \& Squires justify a revenue maximization objective on the grounds that in the short run all inputs are quasi-fixed, so that $x=x_{f}$. This definition is dependent on the output price vector $p$, and defines capacity output as the vector $y^{r} \in Q^{F}\left(x_{f}\right)$ that solves the revenue maximization problem $\max _{\mathrm{y}}\left\{\mathrm{p}^{\top} \mathrm{y}: \mathrm{y} \in \mathrm{Q}\left(\mathrm{x}_{\mathrm{f}}\right)\right\}$, and so the rate of capacity utilization is $C U^{r}=p^{\top} y / p^{\top} y^{r} \leq 1$. In Figure 3 the vectors $y^{a}=y / D_{0}(x, y) \in Q^{F}(x)$ and $y^{G J}=y / D_{0}\left(x_{f}, y\right)$ $\in \mathrm{Q}^{\mathrm{F}}\left(\mathrm{X}_{\mathrm{f}}\right)$ divide revenue-based capacity utilization into three components, an outputoriented technical efficiency term $y / y^{a}=D_{0}(x, y) \leq 1$ and a pair of capacity utilization

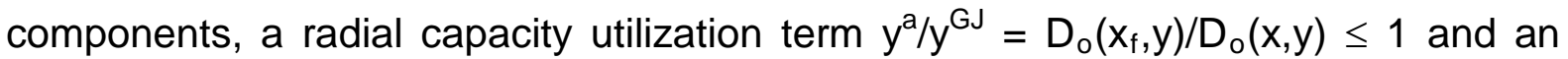
output mix term $p^{\top} y^{G J} / p^{\top} y^{r} \leq 1$ (the latter inequality assuming convexity of $Q^{F}\left(x_{f}\right)$ ). We refer to the three components as wasted capacity, excess capacity, and misallocated capacity, respectively. Wasted capacity and excess capacity have the same interpretations and magnitudes as in the output maximization problem, and misallocated capacity captures the economic value of an optimizing movement along $\mathrm{Q}^{\mathrm{F}}\left(\mathrm{x}_{\mathrm{f}}\right)$ from $\mathrm{y}^{\mathrm{GJ}}$ to $\mathrm{y}^{\mathrm{r}}$ to adjust the output mix to prevailing output prices. Combining 
wasted capacity, excess capacity and misallocated capacity generates an aggregate capacity utilization term $C U^{r}=\left(p^{\top} y / p^{\top} y^{a}\right) \times\left[\left(p^{\top} y^{a} / p^{\top} y^{G J}\right) \times\left(p^{\top} y^{G J} / p^{\top} y^{r}\right)\right]$.

Our third definition solves a variable profit maximization problem, with variable profit $\pi_{v}=p^{\top} y-w_{v}{ }^{\top} x_{v}, w_{v}$ being the variable input price vector and $w_{v}{ }^{\top} x_{v}$ being variable cost. This definition is dependent on two price vectors, $p$ and $w_{v}$. It defines capacity output as the output vector $y^{v \pi} \in Q^{F}\left(x_{f}, x_{v}{ }^{v \pi}\right)$ that, together with $x_{v}{ }^{v \pi}$, solves the variable profit maximization problem $\max _{\mathrm{y}, \mathrm{x}_{\mathrm{v}}}\left\{\mathrm{p}^{\top} \mathrm{y}-\mathrm{w}_{\mathrm{v}}{ }^{\top} \mathrm{x}_{\mathrm{v}}: \mathrm{y} \in \mathrm{Q}\left(\mathrm{x}_{\mathrm{f}}, \mathrm{x}_{\mathrm{v}}{ }^{\mathrm{v} \pi}\right)\right\}$, so that maximum variable profit $\pi_{v}{ }^{v \pi}=p^{\top} y^{v \pi}-W_{v}{ }^{\top} x_{v}{ }^{v \pi}$. The rate of capacity utilization is $C U^{v \pi}$ $=p^{\top} y / p^{\top} y^{v \pi}$. The vectors $y^{a}=y / D_{0}(x, y) \in Q^{F}(x)$ and $y^{b}=y / D_{0}\left(x_{f}, x_{v}{ }^{v \pi}, y\right) \in Q^{F}\left(x_{f}, x_{v}{ }^{v \pi}\right)$ divide $C U^{v \pi}$ into an output-oriented technical efficiency term $y / y^{a}=D_{0}(x, y) \leq 1$ and a

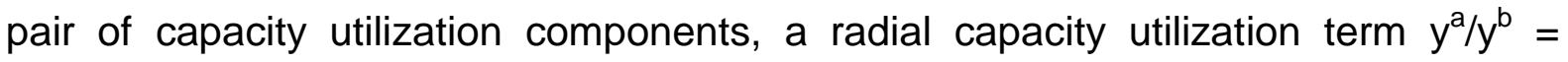
$D_{0}\left(x_{f}, x_{v}{ }^{v \pi}, y\right) / D_{0}(x, y) \leq 1$, and an output mix term $p^{\top} y^{b} / p^{\top} y^{v \pi} \leq 1$ (the latter inequality assuming convexity of $\left.Q^{F}\left(X_{f}, X_{v} v\right)\right)$. As in the revenue maximization problem we refer to the three components as wasted capacity, excess capacity, and misallocated capacity, although excess capacity and misallocated capacity have different magnitudes in the two problems. As in the revenue maximization problem, combining wasted capacity, excess capacity and misallocated capacity generates an aggregate capacity utilization term $C U^{v \pi}=\left(p^{\top} y / p^{\top} y^{a}\right) \times\left[\left(p^{\top} y^{a} / p^{\top} y^{b}\right) \times\left(p^{\top} y^{b} / p^{\top} y^{v \pi}\right)\right]$.

Our final definition follows Coelli et al. (2002), who propose an interesting variant on the variable profit maximization problem. In Figure 3 they replace $y^{v \pi} \in$ $Q^{F}\left(x_{f}, x_{v}{ }^{v \pi}\right)$ with $y^{\text {rec }} \in Q^{F}\left(x_{f}, x_{v}{ }^{\text {rec }}\right)$, where $x_{v}{ }^{\text {rec }} \neq x_{v}{ }^{v \pi}$ and $Q^{F}\left(x_{f}, x_{v}{ }^{\text {rec }}\right)$ is not depicted. $y^{\text {rec }}$ generates the same revenue as $y^{v \pi}$, but the radial constraint causes $p^{\top} y^{\text {rec }}$ $\mathrm{w}_{\mathrm{v}}{ }^{\top} \mathrm{x}_{\mathrm{v}}^{\text {rec }} \leq \mathrm{p}^{\top} \mathrm{y}^{\mathrm{v} \pi}-\mathrm{w}_{\mathrm{v}}{ }^{\top} \mathrm{x}_{\mathrm{V}}^{\mathrm{v} \pi} \Rightarrow \mathrm{w}_{\mathrm{v}}{ }^{\top} \mathrm{x}_{\mathrm{v}}^{\text {rec }} \geq \mathrm{w}_{\mathrm{v}}{ }^{\top} \mathrm{x}_{\mathrm{v}}^{\mathrm{v} \pi}$. However since $\mathrm{y}^{\text {rec }}$ is a radial expansion of $y, y^{a}$ and $y^{b}$, this allows the replacement of output prices with output distance functions in the calculation and decomposition of capacity utilization, as in the initial output maximization problem. In this entirely radial model capacity utilization is defined as the ratio $y / y^{\text {rec }}$, and decomposes somewhat differently than in the variable profit maximization problem as $\mathrm{y} / \mathrm{y}^{\mathrm{GJ}}=\left[\mathrm{y} / \mathrm{y}^{\mathrm{a}} \times \mathrm{y}^{\mathrm{a}} / \mathrm{y}^{\mathrm{rec}}\right] \times \mathrm{y}^{\mathrm{rec}} / \mathrm{y}^{\mathrm{GJ}}$. Coelli et al. refer to the term in brackets as ray economic capacity utilization (hence "rec"), the product of technical inefficiency $y / y^{a}=D_{0}(x, y) \leq 1$ and ray economic capacity net of technical inefficiency $y^{a} / y^{\text {rec }}=D_{0}\left(x_{f}, x_{v}{ }^{\text {rec }}, y\right) / D_{0}(x, y) \leq 1$, and they refer to $y^{\text {rec }} / y^{G J}$ as "economically optimal idle capacity," which shrinks with increases in $p$ and decreases in $\mathrm{W}_{\mathrm{v}}{ }^{7}$

Any of these four output-oriented capacity output definitions can be inserted into expression (1) to generate capacity utilization measures $c U^{c}=p^{\top} y / p^{\top} y^{c}, c=G J$, $r, v \pi$, rec, with corresponding interpretations of potential asset turnover.

The four output-oriented $\mathrm{CU}$ measures are derived from an analytical framework in which $x_{f}$ is a fixed input quantity vector, making fixed cost $C_{f}=w_{f}^{\top} x_{f}$ fixed as well. However it is possible to fix expenditure on fixed inputs without fixing every element of $x_{f}$, thereby allowing one or more elements of $x_{f}$ to be less than fully utilized. Machlup (1952) provided early motivation for doing so by distinguishing 
between indivisibility in purchase and divisibility in use. Somewhat later Maxwell (1965) emphasized the importance of allowing fixed inputs to be less than fully utilized, a distinction also emphasized by Balk (2010). These observations raise the possibility of specifying $w_{f}^{\top} \bar{x}_{f}=\bar{C}_{f}$ and imposing constraints $x_{f} \leq \bar{x}_{f}$, with the weak inequalities allowing fixed inputs in use $x_{f}$ to fall short of the amounts in place $\bar{x}_{f}$, which can be under-utilized but not expanded in the short run. In this case $\bar{x}_{f}$ would generate a strict engineering concept of capacity and $x_{f}$ would generate a managerial concept of capacity. It follows that $w_{f}^{\top} \bar{x}_{f}=\bar{C}_{f}$ but $w_{f}^{\top} x_{f} \leq \bar{C}_{f} \Leftrightarrow\left(w_{f} / \bar{C}_{f}\right) x_{f} \leq$ 1. This formulation allows the construction of four "fixed cost indirect" capacity utilization measures $\mathrm{ICU}^{\mathrm{C}}$ corresponding to the four direct measures $\mathrm{CU}^{\mathrm{C}}$. In this case $\mathrm{Q}\left(\mathrm{x}_{\mathrm{f}}\right)$ is replaced by $\mathrm{Q}\left(\mathrm{w}_{\mathrm{f}} / \overline{\mathrm{C}}_{\mathrm{f}}\right) \supseteq \mathrm{Q}\left(\mathrm{x}_{\mathrm{f}}\right)$, and so each fixed cost indirect ICU measure is smaller than its corresponding direct CU measure. Referring to Figure 3, $Q^{F}(x)$ remains unchanged, but $Q^{F}\left(x_{f}, x_{v}{ }^{v \pi}\right)$ expands to $Q^{F}\left(w_{f} / \bar{C}_{f}, X_{v}{ }^{v \pi}\right), Q^{F}\left(x_{f}, x_{v}{ }^{r e c}\right)$ (which is not depicted) expands to $Q^{F}\left(w_{f} / \bar{C}_{f}, x_{v}{ }^{\text {rec }}\right)$, and $Q^{F}\left(x_{f}\right)$ expands to $Q^{F}\left(w_{f} / \bar{C}_{f}\right)$. The full capacity output quantity vectors increase accordingly. ${ }^{8}$

Any of these four output-oriented fixed cost indirect capacity output definitions can be inserted into expression (1) to generate indirect capacity utilization measures $I C U^{c}, C=G J, r, v \pi$, rec, with corresponding interpretations of potential asset turnover.

The direct and fixed cost indirect analyses are structurally similar; the only difference is the expansion of the direct output sets $Q^{F}\left(x_{f}, x_{v}{ }^{v \pi}\right), Q^{F}\left(x_{f}, x_{v}{ }^{r e c}\right)$ and $Q^{F}\left(x_{f}\right)$ to the fixed cost indirect output sets $Q^{F}\left(w_{f} / \bar{C}_{f}, X_{v}{ }^{v \pi}\right), Q^{F}\left(w_{f} / \bar{C}_{f}, X_{v}{ }^{\text {rec }}\right)$, and $Q^{F}\left(w_{f} / \bar{C}_{f}\right)$, and the corresponding reductions in capacity utilization rates and increases in the full capacity output quantity vectors. Among the virtues of the fixed cost indirect approach are (i) at the firm level it offers flexibility in the allocation of fixed cost budgets when not all individual fixed input constraints are binding, (ii) at the industry level it offers managers or regulators an alternative way of restricting capacity, by assigning quotas to a single variable $\overline{\mathrm{C}}_{f}$ rather than each element of $\mathrm{x}_{\mathrm{f}}$, and (iii) at the analyst level it shrinks the number of direct constraints in an optimization problem.

For subsequent use we collect and rewrite the four direct capacity utilization measures, using the fact that $p^{\top} y / p^{\top} y^{a}=D_{0}(x, y)$, and so

(i) Output maximizing capacity utilization

$$
\begin{aligned}
& C U^{G J}=p^{\top} y / p^{\top} y^{G J}=\left(p^{\top} y / p^{\top} y^{a}\right) \times\left(p^{\top} y^{a} / p^{\top} y^{G J}\right) \\
& \Rightarrow p^{\top} y / p^{\top} y^{a}=C U^{G J} \times\left(p^{\top} y^{G J} / p^{\top} y^{a}\right) \\
& \Rightarrow D_{0}(x, y)=C U^{G J} \times\left(p^{\top} y^{G J} / p^{\top} y^{a}\right)
\end{aligned}
$$

(ii) Revenue maximizing capacity utilization

$$
\begin{aligned}
& C U^{r}=p^{\top} y / p^{\top} y^{r}=\left(p^{\top} y / p^{\top} y^{a}\right) \times\left(p^{\top} y^{a} / p^{\top} y^{r}\right) \\
& \Rightarrow p^{\top} y / p^{\top} y^{a}=C U^{r} \times\left(p^{\top} y^{r} / p^{\top} y^{a}\right) \\
& \Rightarrow D_{0}(x, y)=C U^{r} \times\left(p^{\top} y^{r} / p^{\top} y^{a}\right)
\end{aligned}
$$


(iii) Variable profit maximizing capacity utilization

$$
\begin{aligned}
& C U^{v \pi}=p^{\top} y / p^{\top} y^{v \pi}=\left(p^{\top} y / p^{\top} y^{a}\right) \times\left(p^{\top} y^{a} / p^{\top} y^{v \pi}\right) \\
& \Rightarrow p^{\top} y / p^{\top} y^{a}=C U^{v \pi} \times\left(p^{\top} y^{v \pi} / p^{\top} y^{a}\right) \\
& \Rightarrow D_{0}(x, y)=C U^{v \pi} \times\left(p^{\top} y^{v \pi} / p^{\top} y^{a}\right)
\end{aligned}
$$

(iv) Ray economic variable profit maximizing capacity utilization

$$
\begin{aligned}
& C U^{\text {rec }}=p^{\top} y / p^{\top} y^{\text {rec }}=\left(p^{\top} y / p^{\top} y^{a}\right) \times\left(p^{\top} y^{a} / p^{\top} y^{\text {rec }}\right) \\
& \Rightarrow p^{\top} y / p^{\top} y^{a}=C U^{\text {rec }} \times\left(p^{\top} y^{\text {rec }} / p^{\top} y^{a}\right) \\
& \Rightarrow D_{0}(x, y)=C U^{\text {rec }} \times\left(p^{\top} y^{\text {rec }} / p^{\top} y^{a}\right) .
\end{aligned}
$$

Each of these results states that the output distance function $D_{0}(x, y)$ that measures technical efficiency can be expressed as the product of a capacity utilization measure and the reciprocal of the corresponding measure of net excess capacity. This is a general result, applicable to all four direct capacity utilization measures, and we write

$$
D_{0}(x, y)=C U^{c} \times p^{\top} y^{c} / p^{\top} y^{a},
$$

in which the time period of the output price vector $p$ is deliberately unspecified and the superscript " $c$ " can be defined by $G J, r, v \pi$ or rec. In each case $\mathrm{CU}^{\mathrm{c}}$ is a gross measure, inclusive of output-oriented technical efficiency; there is disagreement about whether waste should be a component of capacity utilization, and our use of separate distance functions enables us to show that waste can be separated from net capacity utilization. In each case the reciprocal of the corresponding measure of net excess capacity $p^{\top} y^{c} / p^{\top} y^{a} \geq 1$ can be interpreted as a measure of plant availability or capacity idleness. Expression (2) generalizes a similar expression in Färe et al. (1989) by incorporating output prices, thereby allowing $c=r$ or $v \pi$ or rec in addition to $c=G J$, and so incorporating possibly non-radial economic definitions of $\mathrm{CU}$ as well as radial technical, or engineering, definitions.

We write the ratio of comparison period to base period versions of expression (2) as

$$
\frac{D_{o}^{1}\left(x^{1}, y^{1}\right)}{D_{o}^{o}\left(x^{0}, y^{o}\right)}=\frac{C U^{1 c}}{C U^{0 c}} \times \frac{\left(p^{T} y^{1 c} / p^{T} y^{1 a}\right)}{\left(p^{T} y^{0 c} / p^{T} y^{0 a}\right)},
$$

which states that change in technical efficiency from base period to comparison period can be expressed as the product of change in capacity utilization and change in available capacity; if the growth of available capacity outpaces the growth of capacity utilization, technical efficiency must decline. Thus expression (3) provides a new framework for a structural explanation for change in technical efficiency. The 
significance of this result, which generalizes a similar decomposition of De Borger \& Kerstens (2000), is that technical efficiency change is a core component of Malmquist productivity indexes, and so expression (3) provides a way of introducing change in capacity utilization as a new component of a Malmquist index of productivity change. We exploit expression (3) for this purpose in Section 4.

\section{Drivers of ROA Change}

In this Section we convert an atemporal duPont triangle to an inter-temporal duPont triangle change. We then develop two models in which change in the rate of capacity utilization, productivity change and price change all affect ROA change.

The ratio of comparison period to base period duPont triangles is

$$
\frac{\pi^{1} / A^{1}}{\pi^{0} / A^{0}}=\frac{\pi^{1} / R^{1}}{\pi^{0} / R^{0}} \times \frac{R^{1} / A^{1}}{R^{0} / A^{0}}
$$

which attributes ROA change to profit margin change and asset turnover change.

We introduce change in the rate of capacity utilization first. Converting the second equality in expression (1) to an inter-temporal context, and using $\mathrm{y}^{\mathrm{c}}$ as the solution vector to any of the input-oriented and direct and indirect output-oriented optimization problems in Section 3, we have

$$
\frac{\pi^{1} / A^{1}}{\pi^{0} / A^{0}}=\frac{\pi^{1} / R^{1}}{\pi^{0} / R^{0}} \times \frac{C U^{1}}{C U^{0}} \times \frac{\mathrm{R}^{c 1} / A^{1}}{\mathrm{R}^{\mathrm{c} 0} / A^{0}}
$$

which attributes ROA change to profit margin change, change in the rate of capacity utilization and change in potential asset turnover. Change in the rate of capacity utilization influences ROA change through its impact on asset turnover change, presumably because increases in $\mathrm{CU}$ bring actual turnover closer to its potential. Neither productivity change nor price recovery change appears in expression (5).

We therefore consider how price change and productivity change influence ROA change. The key is to acknowledge that change in the profit margin derives from price changes and quantity changes, and we write 


$$
\begin{aligned}
\frac{\pi^{1} / \mathrm{R}^{1}}{\pi^{0} / \mathrm{R}^{0}} & =\frac{\pi^{1} / \mathrm{R}^{1}}{\pi_{0}^{1} / \mathrm{R}_{0}^{1}} \times \frac{\pi_{0}^{1} / \mathrm{R}_{0}^{1}}{\pi^{0} / \mathrm{R}^{0}} \\
& =\frac{\pi_{1}^{0} / \mathrm{R}_{1}^{0}}{\pi^{0} / \mathrm{R}^{0}} \times \frac{\pi^{1} / \mathrm{R}^{1}}{\pi_{1}^{0} / \mathrm{R}_{1}^{0}}
\end{aligned}
$$

in which $R_{o}^{1}=p^{0 T} y^{1}$ and $\pi_{o}^{1}=p^{0 \top} y^{1}-w^{0 \top} x^{1}$ in the first equality are comparison period revenue and profit evaluated at base period prices, and $R_{1}^{0}=p^{1 \top} y^{0}$ and $\pi_{1}^{0}=p^{1 \top} y^{0}-$ $w^{1 T} x^{0}$ in the second equality are base period revenue and profit evaluated at comparison period prices. In the first equality the first term on the right side is that part of the margin change that can be attributed solely to price change, since it compares comparison period margins evaluated at comparison period and base period prices. The second term on the right side is that part of the margin change attributable solely to quantity change, since it compares the comparison period margin evaluated at base period prices with the nominal base period margin. We call these two terms a price effect and a quantity effect, respectively. The first term in the second equality is also a price effect since it compares the base period profit margin evaluated at comparison period prices and base period prices. The second term is also a quantity effect because it compares comparison period and base period profit margins evaluated at comparison period prices. The first equality pairs a Paasche price effect with a Laspeyres quantity effect, and the second pairs a Laspeyres price effect with a Paasche quantity effect. The first pairing is more widely used, but the second has its adherents. Frankel (1963), for example, recommends use of Paasche quantity indexes (and, to satisfy the product test, Laspeyres price indexes) because, being based on comparison period price weights, they are better suited to a company's current needs than are the more popular Laspeyres quantity indexes.

We develop two strategies for decomposing the margin change component of ROA change. Our strategy in Section 4.1 has two alternatives. One approach starts with expression (5), with margin change decomposed in expression (6). In the alternative approach we begin with expression (4), with margin change decomposed in expression (6), and we exploit expression (3). Both approaches require cost allocation, and both approaches express the quantity effects in expression (6) in terms of the theoretical Malmquist productivity index proposed by Caves et al. (1982) (CCD). The difference between the two approaches is the location of capacity utilization change as a driver of ROA change. Our strategy in Section 4.2 is to express the quantity effects in expression (6) in terms of empirical Laspeyres, Paasche and Fisher quantity indexes. This strategy does not require cost allocation. Both strategies decompose the quantity effect, but in different ways that provide complementary information 


\subsection{The Theoretical CCD Malmquist Productivity Index Strategy}

As we note above, our application of the CCD Malmquist productivity index to the quantity effects in expression (6) requires cost allocation, a contentious issue that Shubik (2011) calls an open problem in economic theory and accounting. Allocating cost requires creating a unit cost vector $\mathrm{c}=\left(\mathrm{c}_{1} / \mathrm{y}_{1, \ldots,}, \mathrm{C}_{\mathrm{M}} / \mathrm{y}_{\mathrm{M}}\right)$ with $\mathrm{c}_{\mathrm{m}}=$ $\Sigma_{n} w_{n} x_{n m}$ satisfying $c^{\top} y=w^{\top} x$, so that all cost is assigned to outputs, and $c^{\top} y \neq p^{\top} y$ is possible. Allocating variable cost is less challenging, and requires creating a unit variable cost vector $c_{v}$ satisfying $c_{v}{ }^{\top} y=w_{v}{ }^{\top} x_{v}$. Estache \& Grifell-Tatjé (2013) provide an example of the latter. ${ }^{9}$

We begin with the quantity effect $\left(\pi_{0}^{1} / R_{0}^{1}\right) /\left(\pi^{0} / R^{0}\right)$ in the first equality in expression (6). Assuming that cost allocation is feasible, we can write

$$
\begin{aligned}
\pi^{0} & =p^{0 T} y^{0}-w^{0 T} x^{0} \\
& =\left(p^{0}-c^{0}\right)^{\top} y^{0},
\end{aligned}
$$

since $w^{0 T} x^{0}=c^{0 T} y^{0}, c^{0}$ being a vector of base period unit costs of producing each output. Writing base period profit in this way enables us to rewrite the base period profit margin as

$$
\begin{aligned}
\pi^{0} / R^{0} & =\left[\left(p^{0}-c^{0}\right)^{\top} y^{0}\right] / R^{0} \\
& \left.=\left[\left(p^{0}-c^{0}\right) / R^{0}\right]^{\top} y^{0}\right] \\
& =\rho^{0 \top} y^{0},
\end{aligned}
$$

where $\rho^{0}=\left(p^{0}-c^{0}\right) / R^{0}$. Similarly, we can rewrite the real comparison period profit margin as

$$
\begin{aligned}
\left(\pi_{o}^{1} / R_{o}^{1}\right) & =\left[\left(p^{0}-c_{o}^{1}\right)^{\top} y^{1}\right] / R_{o}^{1} \\
& =\left[\left(p^{0}-c_{o}^{1}\right) / R_{0}^{1}\right]^{\top} y^{1} \\
& =\rho_{o}^{1} y^{1},
\end{aligned}
$$

where $c_{0}^{1 T} y^{1}=w^{0 T} x^{1}$ and $\rho_{o}^{1}=\left(p^{0}-c_{o}^{1}\right) / R_{0}^{1}$. Consequently the quantity effect in the first equality in expression (6) can be rewritten as 


$$
\frac{\pi_{0}^{1} / \mathrm{R}_{0}^{1}}{\pi^{0} / \mathrm{R}^{0}}=\frac{\rho_{0}^{1 \mathrm{~T}} \mathrm{y}^{1}}{\rho^{0 \mathrm{~T}} \mathrm{y}^{0}}
$$

\section{Insert Figure 4 About Here}

The next step is to interpret expression (10), which we do with the assistance of Figure 4, in which $\mathrm{T}^{\mathrm{F} 0}$ and $\mathrm{T}^{\mathrm{F} 1}$ are base period and comparison period production frontiers of production sets $\mathrm{T}^{0}$ and $\mathrm{T}^{1}$, analogous to $\mathrm{Q}^{\mathrm{FO}}(\mathrm{x})$ and $\mathrm{Q}^{\mathrm{F} 1}(\mathrm{x})$. We have

$$
\frac{\pi_{o}^{1} / R_{o}^{1}}{\pi^{0} / R^{0}}=\frac{\rho_{o}^{1 T} y^{1} / \rho_{o}^{1 T} y^{C}}{\rho^{0 T} y^{0} / \rho^{0 T} y^{A}} \times \frac{\rho^{0 T} y^{C}}{\rho^{0 T} y^{D}} \times \frac{\rho_{o}^{1 T} y^{D}}{\rho^{0 T} y^{A}},
$$

where $y^{A}=y^{0} / D_{o}^{0}\left(x^{0}, y^{0}\right) \in T^{F 0}, y^{B}=y^{0} / D_{o}^{1}\left(x^{0}, y^{0}\right) \in T^{F 1}, y^{C}=y^{1} / D_{o}^{1}\left(x^{1}, y^{1}\right) \in T^{F 1}$ and $y^{D}=$ $\mathrm{y}^{1} / \mathrm{D}_{\mathrm{o}}^{0}\left(\mathrm{x}^{1}, \mathrm{y}^{1}\right) \in \mathrm{T}^{\mathrm{F} 0}$. We can rewrite expression (11) as

$$
\begin{aligned}
\frac{\pi_{\mathrm{o}}^{1} / \mathrm{R}_{\mathrm{o}}^{1}}{\pi^{0} / \mathrm{R}^{0}} & =\frac{\mathrm{D}_{\mathrm{o}}^{1}\left(\mathrm{x}^{1}, \mathrm{y}^{1}\right)}{\mathrm{D}_{\mathrm{o}}^{0}\left(\mathrm{x}^{0}, \mathrm{y}^{0}\right)} \times \frac{\mathrm{D}_{\mathrm{o}}^{0}\left(\mathrm{x}^{1}, \mathrm{y}^{1}\right)}{\mathrm{D}_{\mathrm{o}}^{1}\left(\mathrm{x}^{1}, \mathrm{y}^{1}\right)} \times \frac{\rho_{0}^{1 \mathrm{~T}} \mathrm{y}^{\mathrm{D}}}{\rho^{0 \mathrm{~T}} \mathrm{y}^{\mathrm{A}}} \\
& =\frac{\mathrm{D}_{\mathrm{o}}^{0}\left(\mathrm{x}^{1}, \mathrm{y}^{1}\right)}{\mathrm{D}_{\mathrm{o}}^{0}\left(\mathrm{x}^{0}, \mathrm{y}^{0}\right)} \times \frac{\rho_{0}^{1 \mathrm{~T}} \mathrm{y}^{\mathrm{D}}}{\rho^{0 \mathrm{~T}} \mathrm{y}^{\mathrm{A}}}
\end{aligned}
$$

in which $\frac{\mathrm{D}_{\mathrm{o}}^{0}\left(\mathrm{x}^{1}, \mathrm{y}^{1}\right)}{\mathrm{D}_{\mathrm{o}}^{0}\left(\mathrm{x}^{0}, \mathrm{y}^{0}\right)}=\frac{\mathrm{D}_{\mathrm{o}}^{1}\left(\mathrm{x}^{1}, \mathrm{y}^{1}\right)}{\mathrm{D}_{\mathrm{o}}^{0}\left(\mathrm{x}^{0}, \mathrm{y}^{0}\right)} \times \frac{\mathrm{D}_{\mathrm{o}}^{0}\left(\mathrm{x}^{1}, \mathrm{y}^{1}\right)}{\mathrm{D}_{\mathrm{o}}^{1}\left(\mathrm{x}^{1}, \mathrm{y}^{1}\right)}$ is an output-oriented base period $\mathrm{CCD}$ Malmquist productivity index. It is apparent from Figure 4 that the two components $\mathrm{D}_{\mathrm{o}}^{1}\left(\mathrm{x}^{1}, \mathrm{y}^{1}\right) / \mathrm{D}_{\mathrm{o}}^{0}\left(\mathrm{x}^{0}, \mathrm{y}^{0}\right)$ and $\mathrm{D}_{\mathrm{o}}^{0}\left(\mathrm{x}^{1}, \mathrm{y}^{1}\right) / \mathrm{D}_{\mathrm{o}}^{1}\left(\mathrm{x}^{1}, \mathrm{y}^{1}\right)$ measure technical efficiency change and technical change $\left(\right.$ at $\left.x^{1}\right)$, respectively. Consequently we can rewrite expression (12) as

$$
\frac{\pi_{o}^{1} / R_{o}^{1}}{\pi^{0} / R^{0}}=M_{o C C D}^{0}\left(x^{1}, x^{0}, y^{1}, y^{0}\right) \times \frac{\rho_{o}^{1 T} y^{D}}{\rho^{0 T} y^{A}}
$$

The term $\mathrm{M}_{\mathrm{o} C \mathrm{CD}}^{0}\left(\mathrm{x}^{1}, \mathrm{x}^{0}, \mathrm{y}^{1}, \mathrm{y}^{0}\right)$ captures the impacts of technical efficiency change and technical change, and nothing else. The term $\rho_{0}^{1 \mathrm{~T}} \mathrm{y}^{\mathrm{D}} / \rho^{0 \mathrm{~T}} \mathrm{y}^{\mathrm{A}}$ measures the impact of size change that captures the joint impacts of economies of scale and 
diversification that is absent from $\mathrm{M}_{\mathrm{O} C \mathrm{CD}}^{0}\left(\mathrm{x}^{1}, \mathrm{x}^{0}, \mathrm{y}^{1}, \mathrm{y}^{0}\right)$, and corresponds to the movement along $T^{F 0}$ from $\left(x^{0}, y^{A}\right)$ to $\left(x^{1}, y^{D}\right)$ in Figure 4. Thus the quantity effect $\left(\pi_{0}^{1} / R_{0}^{1}\right) /\left(\pi^{0} / R^{0}\right)$ is a measure of productivity change, because it includes the impact of size change along with the impacts of technical efficiency change and technical change. ${ }^{10}$

Substituting expression (13) into the first equality in expression (6), and substituting the resulting profit margin decomposition into expression (5), yields a decomposition of ROA change incorporating (and decomposing and augmenting) a base period CCD Malmquist productivity index

$$
\frac{\pi^{1} / A^{1}}{\pi^{0} / A^{0}}=\frac{\pi^{1} / \mathrm{R}^{1}}{\pi_{o}^{1} / \mathrm{R}_{\mathrm{o}}^{1}} \times\left\{\frac{\mathrm{D}_{\mathrm{o}}^{1}\left(\mathrm{x}^{1}, \mathrm{y}^{1}\right)}{\mathrm{D}_{\mathrm{o}}^{0}\left(\mathrm{x}^{0}, \mathrm{y}^{0}\right)} \times \frac{\mathrm{D}_{\mathrm{o}}^{0}\left(\mathrm{x}^{1}, \mathrm{y}^{1}\right)}{\mathrm{D}_{\mathrm{o}}^{1}\left(\mathrm{x}^{1}, \mathrm{y}^{1}\right)} \times \frac{\rho_{\mathrm{o}}^{1 \mathrm{~T}} \mathrm{y}^{\mathrm{D}}}{\rho^{0 \mathrm{~T}} \mathrm{y}^{\mathrm{A}}}\right\} \times \frac{\mathrm{CU^{1 }}}{\mathrm{CU^{0 }}} \times \frac{\mathrm{R}^{\mathrm{c} 1} / \mathrm{A}^{1}}{\mathrm{R}^{\mathrm{c} 0} / \mathrm{A}^{0}},
$$

in which $\mathrm{CU}^{1} / \mathrm{CU}^{0}=\left(\mathrm{p}^{1 \mathrm{~T}} \mathrm{y}^{1} / \mathrm{p}^{1 \mathrm{~T}} \mathrm{y}^{\mathrm{c} 1}\right) /\left(\mathrm{p}^{0 \mathrm{~T}} \mathrm{y}^{0} / \mathrm{p}^{0 \mathrm{~T}} \mathrm{y}^{\mathrm{c} 0}\right)$ and $\mathrm{R}^{\mathrm{ct}}=\mathrm{p}^{\mathrm{tT}} \mathrm{y}^{\mathrm{ct}}, \mathrm{t}=0,1$. Expression (14) attributes ROA change to price change, three components of productivity change, change in capacity utilization and change in potential asset turnover.

Starting with expression (5) and the first equality in expression (6) leads to a decomposition of ROA change in expression (14) built on a base period CCD Malmquist productivity index and a size change term calculated along base period technology. Starting with expression (5) and the second equality in expression (6) and following the same procedures generates a decomposition of ROA change built on a comparison period CCD Malmquist productivity index and a size change term calculated along comparison period technology. Taking the geometric mean of the two decompositions generates a decomposition of ROA change incorporating a geometric mean CCD Malmquist productivity index given by

$$
\begin{aligned}
\frac{\pi^{1} / \mathrm{A}^{1}}{\pi^{0} / \mathrm{A}^{0}}= & {\left[\frac{\pi^{1} / \mathrm{R}^{1}}{\pi_{\mathrm{o}}^{1} / \mathrm{R}_{\mathrm{o}}^{1}} \times \frac{\pi_{1}^{0} / \mathrm{R}_{1}^{0}}{\pi^{0} / \mathrm{R}^{0}}\right]^{\frac{1}{2}} } \\
& \times\left\{\frac{\mathrm{D}_{\mathrm{o}}^{1}\left(\mathrm{x}^{1}, \mathrm{y}^{1}\right)}{\mathrm{D}_{\mathrm{o}}^{0}\left(\mathrm{x}^{0}, \mathrm{y}^{0}\right)} \times\left[\frac{\mathrm{D}_{\mathrm{o}}^{0}\left(\mathrm{x}^{1}, \mathrm{y}^{1}\right)}{\mathrm{D}_{\mathrm{o}}^{1}\left(\mathrm{x}^{1}, \mathrm{y}^{1}\right)} \times \frac{\mathrm{D}_{\mathrm{o}}^{0}\left(\mathrm{x}^{0}, \mathrm{y}^{0}\right)}{\mathrm{D}_{\mathrm{o}}^{1}\left(\mathrm{x}^{0}, \mathrm{y}^{0}\right)}\right]^{\frac{1}{2}} \times\left[\frac{\rho_{\mathrm{o}}^{1 \mathrm{~T}} \mathrm{y}^{\mathrm{D}}}{\rho^{0 \mathrm{~T}} \mathrm{y}^{\mathrm{A}}} \times \frac{\rho^{1 \mathrm{~T}} \mathrm{y}^{\mathrm{C}}}{\rho_{1}^{0 \mathrm{~T}} \mathrm{y}^{\mathrm{B}}}\right]^{\frac{1}{2}}\right\} \\
& \times \frac{\mathrm{CU}^{1}}{\mathrm{CU}^{0}} \times \frac{\mathrm{R}^{\mathrm{c} 1} / \mathrm{A}^{1}}{\mathrm{R}^{\mathrm{c} 0} / \mathrm{A}^{0}},
\end{aligned}
$$


which mimics expression (4) by expressing ROA change as the product of margin change (the first two rows) and asset turnover change (the third row). Margin change is the product of price change (the first row) and productivity change (the second row). Price change is the geometric mean of the two price effects in expression (6). Productivity change is the product of a geometric mean CCD Malmquist productivity index and a geometric mean size change term. Finally, asset turnover change is the product of change in capacity utilization and change in potential asset turnover. Although change in capacity utilization exerts a positive influence on ROA change, it does so without influencing productivity change.

However Schultze (1963), former chairman of the US Council of Economic Advisors and former director of the US Bureau of the Budget, and Kendrick \& Grossman (1980) have argued, and provided supporting empirical evidence, that change in the rate of capacity utilization exerts a positive influence on productivity change at the aggregate level. Many subsequent writers concur. Another literature, smaller perhaps, suggests that profit margins vary directly with the rate of capacity utilization, although the mechanism through which capacity utilization change influences margin change is unspecified. Both literatures enjoy empirical support. Accordingly we next introduce capacity utilization change as a driver of productivity change, and so margin change, in an expression for ROA change.

We incorporate $\mathrm{CU}$ change as a driver of productivity change by combining expressions (4) and (6), rather than expressions (5) and (6) as above. Following the same procedures as above generates the geometric mean decomposition of ROA change

$$
\begin{aligned}
\frac{\pi^{1} / A^{1}}{\pi^{0} / A^{0}}= & {\left[\frac{\pi^{1} / \mathrm{R}^{1}}{\pi_{0}^{1} / \mathrm{R}_{\mathrm{o}}^{1}} \times \frac{\pi_{1}^{0} / \mathrm{R}_{1}^{0}}{\pi^{0} / \mathrm{R}^{0}}\right]^{\frac{1}{2}} } \\
& \times\left\{\frac{\mathrm{D}_{0}^{1}\left(\mathrm{x}^{1}, \mathrm{y}^{1}\right)}{\mathrm{D}_{\mathrm{o}}^{0}\left(\mathrm{x}^{0}, \mathrm{y}^{0}\right)} \times\left[\frac{\mathrm{D}_{\mathrm{o}}^{0}\left(\mathrm{x}^{1}, \mathrm{y}^{1}\right)}{\mathrm{D}_{\mathrm{o}}^{1}\left(\mathrm{x}^{1}, \mathrm{y}^{1}\right)} \times \frac{\mathrm{D}_{\mathrm{o}}^{0}\left(\mathrm{x}^{0}, \mathrm{y}^{0}\right)}{\mathrm{D}_{\mathrm{o}}^{1}\left(\mathrm{x}^{0}, \mathrm{y}^{0}\right)}\right]^{\frac{1}{2}} \times\left[\frac{\rho_{\mathrm{o}}^{1 \mathrm{~T}} \mathrm{y}^{\mathrm{D}}}{\rho^{0 \mathrm{~T}} \mathrm{y}^{\mathrm{A}}} \times \frac{\rho^{1 \mathrm{~T}} \mathrm{y}^{\mathrm{C}}}{\rho_{1}^{0 \mathrm{~T}} \mathrm{y}^{\mathrm{B}}}\right]^{\frac{1}{2}}\right\} \\
& \times \frac{\mathrm{R}^{1} / \mathrm{A}^{1}}{\mathrm{R}^{0} / \mathrm{A}^{0}},
\end{aligned}
$$

which decomposes ROA change into margin change and asset turnover change, with margin change expressed as the product of price change and productivity change. We now introduce expression (3), which states that technical efficiency change can be expressed as the product of change in capacity utilization and change in available capacity. Expression (16) contains a technical efficiency change component $\mathrm{D}_{0}^{1}\left(\mathrm{x}^{1}, \mathrm{y}^{1}\right) / \mathrm{D}_{0}^{0}\left(\mathrm{x}^{0}, \mathrm{y}^{0}\right)$ as a driver of productivity change. Replacing the 
technical efficiency change component with the right side of expression (3) generates an alternative decomposition of ROA change also based on an augmented (by a size change term) geometric mean CCD Malmquist productivity index given by

$$
\begin{aligned}
\frac{\pi^{1} / A^{1}}{\pi^{0} / A^{0}} & =\left[\frac{\pi^{1} / R^{1}}{\pi_{o}^{1} / R_{o}^{1}} \times \frac{\pi_{1}^{0} / R_{1}^{0}}{\pi^{0} / R^{0}}\right]^{\frac{1}{2}} \\
& \times\left\{\frac{C U^{1 c}}{C U^{0 c}} \times \frac{p^{T} y^{1 c} / p^{T} y^{1 a}}{p^{T} y^{0 c} / p^{T} y^{0 a}} \times\left[\frac{D_{o}^{0}\left(x^{1}, y^{1}\right)}{D_{o}^{1}\left(x^{1}, y^{1}\right)} \times \frac{D_{o}^{0}\left(x^{0}, y^{0}\right)}{D_{o}^{1}\left(x^{0}, y^{0}\right)}\right]^{\frac{1}{2}} \times\left[\frac{\rho_{o}^{1 T} y^{D}}{\rho^{0 T} y^{A}} \times \frac{\rho^{1 T} y^{C}}{\rho_{1}^{0 T} y^{B}}\right]^{\frac{1}{2}}\right\} \\
& \times \frac{R^{1} / A^{1}}{R^{0} / A^{0}},
\end{aligned}
$$

which decomposes ROA change into the product of margin change and asset turnover change. Margin change is the product of price change and productivity change. Productivity change is the product of $\mathrm{CU}$ change, change in available capacity, technical change and size change.

Expressions (15) and (17) provide alternative decompositions of ROA change incorporating productivity change and change in capacity utilization. The difference between them is the placement of $\mathrm{CU}$ change as a driver of ROA change. In expression (15) $\mathrm{CU}$ change is a component of asset turnover change, the idea being that increases in CU bring actual turnover closer to its potential. In expression (17) $\mathrm{CU}$ change is a component of productivity change, which in turn is a driver of margin change. Consistent with the arguments and findings of Schultze and others, increases in $\mathrm{CU}$ exert a positive impact on productivity change, and hence margin change. ${ }^{11}$

Summarizing Section 4.1, we set out to decompose ROA change from one time period to the next. Our strategy is based on the CCD Malmquist productivity index, which is known to decompose into the product of technical efficiency change and technical change. It is also known to lack a size change component, and we have introduced what we believe is a new size change term. In Section 4.2 we relate this theoretical productivity effect with an empirical price-based productivity index. A key insight contained in expression (3) has led us to a pair of decompositions of ROA change in expressions (15) and (17). These expressions are devoid of financial ratios (with the partial exception of the actual and potential asset turnover terms), and contain relevant economic drivers of ROA change. Change in capacity utilization plays one role in expression (15) and a different role in expression (17). Both decompositions are based on the assumption that cost allocation is feasible, 
although both would go through under a weaker feasibility condition of variable cost allocation with only minor terminological and notational changes. Both decompositions are incomplete, however, because they do not express the price effect in terms of change in price recovery. The index number strategy we introduce in Section 4.2 does express the price effect in terms of a price recovery index.

\subsection{The Empirical Index Number Strategy}

In Section 4.1 we use an augmented (by a size change component) CCD productivity index to interpret the quantity effects in expression (6) as productivity effects, on the assumption that cost allocation is feasible. However we are unable to provide an analogous interpretation of the price effect as a price recovery effect. Such an interpretation appears to require empirical quantity- and price-based indexes.

A few mathematical manipulations enable us to write the price effect in the first equality of expression (6) as

$$
\frac{\pi^{1} / \mathrm{R}^{1}}{\pi_{\mathrm{o}}^{1} / \mathrm{R}_{\mathrm{o}}^{1}}=\frac{\pi^{1}}{\mathrm{R}^{1}-\left(\frac{\mathrm{P}_{\mathrm{P}}}{\mathrm{W}_{\mathrm{P}}}\right) \mathrm{W}^{1 \mathrm{~T} \mathrm{X}^{1}}}
$$

in which $P_{P} N_{P}$ is a Paasche price recovery index, with $P_{P} W_{P} \gtreqless 1 \Leftrightarrow \frac{\pi^{1} / R^{1}}{\pi_{o}^{1} / R_{o}^{1}} \gtreqless 1$. Expression (18) contains comparison period and base period prices, but only comparison period quantities, and shows the contribution of price recovery to profit margin change from a Paasche perspective.

We follow the same strategy to write the quantity effect in the first equality of expression (9) as

$$
\frac{\pi_{\mathrm{o}}^{1} / \mathrm{R}_{\mathrm{o}}^{1}}{\pi^{0} / \mathrm{R}^{0}}=\frac{\pi_{\mathrm{o}}^{1}}{\mathrm{R}_{\mathrm{o}}^{1}-\left(\frac{\mathrm{Y}_{\mathrm{L}}}{\mathrm{X}_{\mathrm{L}}}\right) \mathrm{w}^{0 \mathrm{~T}} \mathrm{X}^{1}}
$$

in which $Y_{L} / X_{L}$ is a Laspeyres productivity index, with $Y_{L} / X_{L} \gtreqless 1 \Leftrightarrow \frac{\pi_{0}^{1} / R_{0}^{1}}{\pi^{0} / R^{0}} \gtreqless 1$. Expression (19) contains comparison period and base period quantities, but only base period prices, and shows the contribution of productivity change to profit margin change from a Laspeyres perspective. Expression (13) provides a decomposition of expression (19) into the product of a base period CCD Malmquist productivity index and a measure of size change calculated along base period technology. 
Substituting expressions (18) and (19) into expression (5) yields a decomposition of ROA change based on empirical price and quantity indexes

$$
\begin{aligned}
\frac{\pi^{1} / A^{1}}{\pi^{0} / A^{0}}= & \frac{\pi^{1}}{R^{1}-\left(\frac{P_{P}}{W_{P}}\right) W^{1 T} X^{1}} \times \frac{\pi_{o}^{1}}{R_{o}^{1}-\left(\frac{Y_{L}}{X_{L}}\right) W^{0 T} X^{1}} \\
& \times \frac{C U^{c 1}}{C U^{c 0}} \times \frac{R^{c 1} / A^{1}}{R^{c 0} / A^{0}}
\end{aligned}
$$

which attributes ROA change to price recovery change, productivity change, change in capacity utilization and change in potential asset turnover.

Following the same procedures with the second line of expression (6) generates a similar decomposition of ROA change, with Laspeyres price recovery component and Paasche productivity component. Taking the geometric mean of the two yields

$$
\begin{aligned}
\frac{\pi^{1} / \mathrm{A}^{1}}{\pi^{0} / \mathrm{A}^{0}}=\left[\frac{\pi^{1}}{\mathrm{R}^{1}-\left(\frac{\mathrm{P}_{\mathrm{P}}}{\mathrm{W}_{\mathrm{P}}}\right) \mathrm{w}^{1 \mathrm{~T}} \mathrm{X}^{1}} \times \frac{\pi_{1}^{0}}{\mathrm{R}_{1}^{0}-\left(\frac{\mathrm{P}_{\mathrm{L}}}{\mathrm{W}_{\mathrm{L}}}\right) \mathrm{w}^{1 \mathrm{~T} \mathrm{X}^{0}}}\right]^{1 / 2} \\
\times\left[\frac{\pi_{\mathrm{o}}^{1}}{\mathrm{R}_{\mathrm{o}}^{1}-\left(\frac{\mathrm{Y}_{\mathrm{L}}}{\mathrm{X}_{\mathrm{L}}}\right) \mathrm{w}^{0 \mathrm{~T}} \mathrm{X}^{1}} \times \frac{\pi^{1}}{\mathrm{R}^{1}-\left(\frac{\mathrm{Y}_{\mathrm{P}}}{\mathrm{X}_{\mathrm{P}}}\right) \mathrm{w}^{1 \mathrm{~T} \mathrm{X}^{1}}}\right]^{1 / 2} \\
\\
\times \frac{\mathrm{CU}^{\mathrm{c} 1}}{\mathrm{CU}^{\mathrm{c} 0}} \times \frac{\mathrm{R}^{\mathrm{c} 1} / \mathrm{A}^{1}}{\mathrm{R}^{\mathrm{c} 0} / \mathrm{A}^{0}} .
\end{aligned}
$$

Expression (21) decomposes ROA change into a price recovery index that is the geometric mean of Paasche and Laspeyres price recovery indexes, a productivity index that is the geometric mean of Laspeyres and Paasche productivity indexes, capacity utilization change and change in potential asset turnover.

Recalling the relationship between base period expressions (13) and (19), and an analogous relationship equating the Paasche productivity component of expression (21) with the product of a comparison period CCD Malmquist productivity index and a measure of size change calculated along comparison period technology, enables us to exploit the second row of expression (15) to rewrite expression (21) as 


$$
\begin{aligned}
& \frac{\pi^{1} / A^{1}}{\pi^{0} / A^{0}}=\left[\frac{\pi^{1}}{R^{1}-\left(\frac{P_{P}}{W_{P}}\right) W^{1 T} X^{1}} \times \frac{\pi_{1}^{0}}{R_{1}^{0}-\left(\frac{P_{L}}{W_{L}}\right) w^{1 T} X^{0}}\right]^{1 / 2} \\
& \times\left[M_{o C C D}^{0}\left(x^{1}, x^{0}, y^{1}, y^{0}\right) \times M_{o C C D}^{1}\left(x^{1}, x^{0}, y^{1}, y^{0}\right)\right]^{1 / 2} \\
& \times\left[\frac{\rho_{\mathrm{o}}^{1 \mathrm{~T}} \mathrm{y}^{\mathrm{D}}}{\rho^{0 \mathrm{~T}} \mathrm{y}^{\mathrm{A}}} \times \frac{\rho^{1 \mathrm{~T}} \mathrm{y}^{\mathrm{C}}}{\rho_{1}^{0 \mathrm{~T}} \mathrm{y}^{\mathrm{B}}}\right]^{1 / 2} \times \frac{\mathrm{CU^{ \textrm {c } 1 }}}{\mathrm{CU^{ \textrm {c } 0 }}} \times \frac{\mathrm{R}^{\mathrm{c} 1} / \mathrm{A}^{1}}{\mathrm{R}^{\mathrm{c} 0} / \mathrm{A}^{0}} .
\end{aligned}
$$

Expression (22) decomposes ROA change using an empirical price recovery index and a theoretical productivity index consisting of a geometric mean CCD Malmquist index augmented with a geometric mean size effect. The final two components, $\mathrm{CU}$ change and change in potential asset turnover, can be merged into change in asset turnover.

In expressions (21) and (22) CU change influences ROA change through its impact on change in asset turnover. An alternative strategy is to substitute price recovery and productivity indexes into expression (4) rather than expression (5), and make use of Gold's expression $Y / X=Y^{c} / X \times Y / Y^{c}$, which states that productivity change is the product of potential productivity change $Y^{c} / X$ and capacity utilization change $Y / Y^{c}$. Assigning Laspeyres and Paasche structure to $Y, Y^{c}$ and $X$ yields the ROA decomposition

$$
\begin{aligned}
\frac{\pi^{1} / \mathrm{A}^{1}}{\pi^{0} / \mathrm{A}^{0}}= & {\left[\frac{\pi^{1}}{\mathrm{R}^{1}-\left(\frac{\mathrm{P}_{\mathrm{P}}}{\mathrm{W}_{\mathrm{P}}}\right) \mathrm{w}^{1 \mathrm{~T}} \mathrm{X}^{1}} \times \frac{\pi_{1}^{0}}{\mathrm{R}_{1}^{0}-\left(\frac{\mathrm{P}_{\mathrm{L}}}{\mathrm{W}_{\mathrm{L}}}\right) \mathrm{w}^{1 \mathrm{~T} \mathrm{X}^{0}}}\right]^{1 / 2} } \\
& \times\left[\frac{\pi_{\mathrm{O}}^{1}}{\mathrm{R}_{\mathrm{O}}^{1}-\left(\frac{\mathrm{Y}_{\mathrm{L}}}{\mathrm{Y}_{\mathrm{L}}^{\mathrm{c}}}\right)\left(\frac{\mathrm{Y}_{\mathrm{L}}^{\mathrm{C}}}{\mathrm{X}_{\mathrm{L}}}\right) \mathrm{w}^{0 \mathrm{~T}_{\mathrm{X}} 1}} \times \frac{\pi^{1}}{\mathrm{R}^{1}-\left(\frac{\mathrm{Y}_{\mathrm{P}}}{\mathrm{Y}_{\mathrm{P}}^{\mathrm{c}}}\right)\left(\frac{\mathrm{Y}_{\mathrm{P}}^{\mathrm{C}}}{\mathrm{X}_{\mathrm{P}}}\right) \mathrm{w}^{1 \mathrm{~T}_{\mathrm{X}^{1}}}}\right]^{1 / 2} \\
& \times \frac{\mathrm{R}^{1} / \mathrm{A}^{1}}{\mathrm{R}^{0} / \mathrm{A}^{0}} .
\end{aligned}
$$

Expressions (21) - (23) provide three alternative empirical price-based decompositions of ROA change. Expressions (21) and (23) are exclusively price- 
based, and differ in the role they assign to $\mathrm{CU}$ change. Expression (22) replaces a price-based productivity term with a theoretical productivity term.

The quantity vectors needed to implement the ROA change decompositions in price-based expressions (21) - (23) (and technology-based expressions (15) and (17) in Section 4.1) are either observed $\left(\mathrm{y}^{1}, \mathrm{y}^{0}, \mathrm{x}^{1}, \mathrm{x}^{0}\right)$ or solutions to optimization problems specified in Section $3\left(\mathrm{y}^{\mathrm{c}}, \mathrm{y}^{\mathrm{c} 1}\right)$, or radial expansions or contractions of observed quantity vectors as in Section 4.1. The two sets of decompositions are interpreted in exactly the same way; the only difference is that one uses distance functions and the other uses prices to decompose productivity change and to measure change in capacity utilization.

The objective and structure of Section 4.2 replicate those of Section 4.1, replacing a theoretical technology-based framework with an empirical price-based framework. Our final decompositions of ROA change in expressions (21) - (23) have the same structure as the two final decompositions in expressions (15) and (17) in Section 4.1, but decompositions (21) - (23) are complete, in the sense that they express the price and quantity effects of expression (6) in terms of Paasche and Laspeyres price recovery and productivity indexes. We call the price and quantity effects Fisher effects because they are geometric means of Paasche and Laspeyres price and quantity effects, although these effects do not contain explicit Fisher price recovery and productivity indexes. ${ }^{12}$ Nonetheless, expressions (21) - (23) attribute ROA change to three primary drivers: price recovery change, productivity change and change in asset turnover. Capacity utilization change influences ROA change through its impact on asset turnover in expressions (21) and (23), and through its impact on productivity change in expression (22).

\section{External Capacity Constraints}

Thus far we have treated capacity utilization as a short run phenomenon created by fixed input quantity constraints $x_{f}$ or a weaker fixed input expenditure constraint $C_{f}$. These capacity constraints are internal to the firm. However firms also face external capacity constraints that have financial consequences. Mining firms are constrained by health, safety and environmental regulations, by industrial action, by weather conditions, by inadequate social infrastructure (e.g., housing and schools near mine sites) that make hiring difficult and exacerbate chronic skills shortages, and especially by inadequate transport infrastructure that inhibits their ability to move minerals from mines to ports to satisfy demand in a timely fashion. ${ }^{13}$ Fishers are constrained by a variety of fishery management policies intended to limit catch in a fishery in pursuit of maximum economic or sustainable yield. Input-oriented policies constrain fisher fixed input use, or "effort," and more effective output-oriented policies impose total allowable catch (TAC) limits on the fishery, often combined with individual transferrable quota (ITQ) allocations among fishers. In both industries 
external capacity constraints may make at least some internal capacity constraints redundant for at least some firms at least some of the time.

\section{Insert Figure 5 About Here}

Figure 5 augments Figure 3 with an external frontier $\mathrm{Q}^{\mathrm{F}}(\mathrm{Z})$. The three internal frontiers are interpreted as before. The external frontier $\mathrm{Q}^{\mathrm{F}}(\mathrm{Z})$ represents the collective impacts of industry management practices, regulations, supply chain bottlenecks and other production-limiting capacity constraints unrelated to the quantity or the cost of fixed inputs used by a firm.

Using the output maximization framework of Gold and Johansen to illustrate, output vector $y$ has wasted capacity $p^{\top} y / p^{\top} y^{a}$ and excess capacity $p^{\top} y^{a} / p^{\top} y^{G J}$. It also has over-capacity $p^{\top} y^{G J} / p^{T} y^{E}$; it has the capacity to produce $y^{G J}$, but the external constraint $\mathrm{Q}^{\mathrm{F}}(\mathrm{Z})$ prevents it from doing so. Overcapacity in mining results largely from diffuse and uncoordinated ownership of links in the supply chain. Reducing overcapacity by making improvements to the supply chain, for example, would increase primarily export-generated revenue and employment by shifting $\mathrm{Q}^{\mathrm{F}}(\mathrm{Z})$ outward, thereby reducing $p^{\top} y^{G J} / p^{\top} y^{E}$. Overcapacity in a fishery results from the opposite problem, lack of ownership rights, which creates a tragedy of the commons; external capacity constraints such as TAC and ITQ are intended to create individual property rights and alter fisher incentives. Reducing overcapacity in a fishery by tightening TAC, for example, would reduce revenue and employment by shifting $\mathrm{Q}^{\mathrm{F}}(\mathrm{Z})$ inward, thereby increasing $\mathrm{p}^{\top} \mathrm{y}^{\mathrm{GJ}} / \mathrm{p}^{\top} \mathrm{y}^{\mathrm{E}}$, at least in the short run, although it may prevent overharvesting of the fish stock and promote profitability of the fishery. The interpretation is similar in the revenue maximization and variable profit maximization frameworks, although $\mathrm{y}^{\mathrm{E}}$ would not be a revenue maximizing or variable profit maximizing output given output price vector $\mathrm{p}$. Since $\mathrm{Q}(\mathrm{Z}) \subset \mathrm{Q}\left(\mathrm{x}_{\mathrm{f}}\right)$, the internal capacity constraints associated with the output maximization and revenue maximization frameworks are rendered redundant by $Z$. Although $Q(Z) \not \subset Q\left(x_{f}, x_{v}{ }^{v \pi}\right)$, it does make previously optimal $\mathrm{y}^{\mathrm{rec}}$ and $\mathrm{y}^{\mathrm{v} \pi}$ infeasible. ${ }^{14}$

$\mathrm{Q}^{\mathrm{F}}(\mathrm{Z})$ is not necessarily a neutral contraction of $\mathrm{Q}^{\mathrm{F}}\left(\mathrm{x}_{\mathrm{f}}\right)$, and may constrain some outputs proportionally more than others, and constrain some firms more than others, inducing exit by relatively weak firms that creates a more efficient industry structure. The story would be similar based on input-oriented Figure 2; SAC $\left(y, w_{v}, x_{f}\right)$ would shift up to $\operatorname{SAC}\left(\mathrm{y}, \mathrm{w}_{\mathrm{v}}, \mathrm{x}_{\mathrm{f}}, \mathrm{Z}\right)$, perhaps with a larger upward shift for some elements of $y$ than others, perhaps also for some firms more than others, each leading to a restructuring of the industry. ${ }^{15}$

\section{Summary and Conclusions}


The financial health of a business is typically characterized in terms of various financial ratios. The duPont triangle formalizes the characterization, measuring financial health with return on assets, which is expressed as the product of two other financial ratios, the profit margin and asset turnover. Gold and subsequent writers have hypothesized that the rate of capacity utilization also influences return on assets, and so in Section 3 we express return on assets as the product of the profit margin, the rate of capacity utilization, and potential asset turnover. This is the first step in our objective of introducing economic variables into the duPont triangle. We then propose a series of input-oriented and output-oriented measures of capacity output, from which alternative measures of the rate of capacity utilization are derived.

The second step in our objective is the introduction of productivity and price recovery as drivers of return on assets. However since these two variables are change variables, describing change from one period to the next, in Section 4 we convert the duPont triangle, expressed as the product of level variables, to an intertemporal ratio of duPont triangles in which ROA change is expressed as the product of change variables. We develop two analytical frameworks within which to create an economic decomposition of ROA change in terms of its economic drivers. The first is technology-based, and exploits a theoretical productivity index and the second is based on empirical price and quantity indexes. Both frameworks provide valuable information to management concerning the likely sources of changes in its financial performance.

The technology-based decompositions appear in expressions (15) and (17) in Section 4.1, which decompose ROA change into the product of three primary drivers, price recovery change (although not in explicit form), productivity change and change in asset turnover. A fourth driver, change in capacity utilization, influences ROA change by influencing asset turnover in expression (15), and by influencing productivity change in expression (17).

The price-based decompositions appear in expressions (21) - (23) in Section 4.2, which also decompose ROA change into the same four drivers. Change in capacity utilization acts as a driver of change in asset turnover in expressions (21) and (22), and as a driver of productivity change in expression (23). The structure of decompositions (15) and (21) is similar, as is the somewhat different structure of expressions (17) and (23).

The two frameworks have offsetting strengths. The technology-based framework decomposes the productivity change term into the product of either three or four economic drivers, although it requires cost allocation, and it does not introduce an explicit expression for price recovery change. The price-based framework generates explicit expressions for both price recovery change and productivity change, and it does not require cost allocation, although the expression for productivity change does not decompose by economic driver. Hybrid expression (22) shares features of both frameworks; it contains an explicit expression for price 
recovery change, it decomposes productivity change by economic driver, and it decomposes change in asset turnover, although it requires cost allocation.

In Section 5 we extend the analytical framework by showing how external capacity constraints influence capacity output, capacity utilization and return on assets, and we provide empirical evidence from mining and fisheries.

Summarizing, the duPont triangle measures financial performance with ROA, and decomposes ROA into the product of a pair of managerially informative financial ratios. We begin by converting this atemporal relationship to an inter-temporal one, and we assert that the two financial ratios must have economic drivers. We then develop a pair of analytical frameworks containing change in a modified financial ratio, change in capacity utilization, price recovery change and productivity change as drivers of ROA change. 
Figures

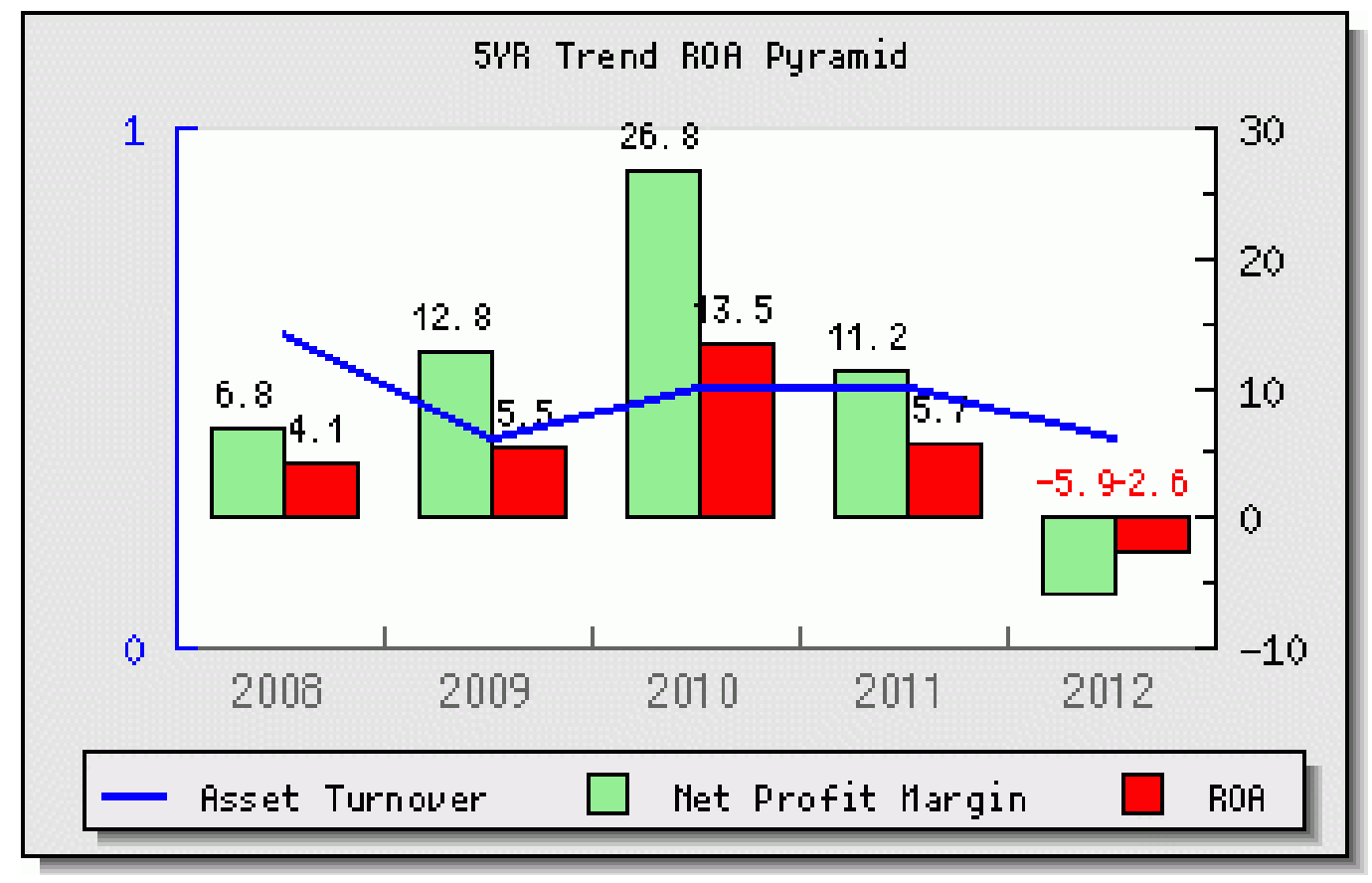

Figure 1 The duPont Triangle at Rio Tinto 


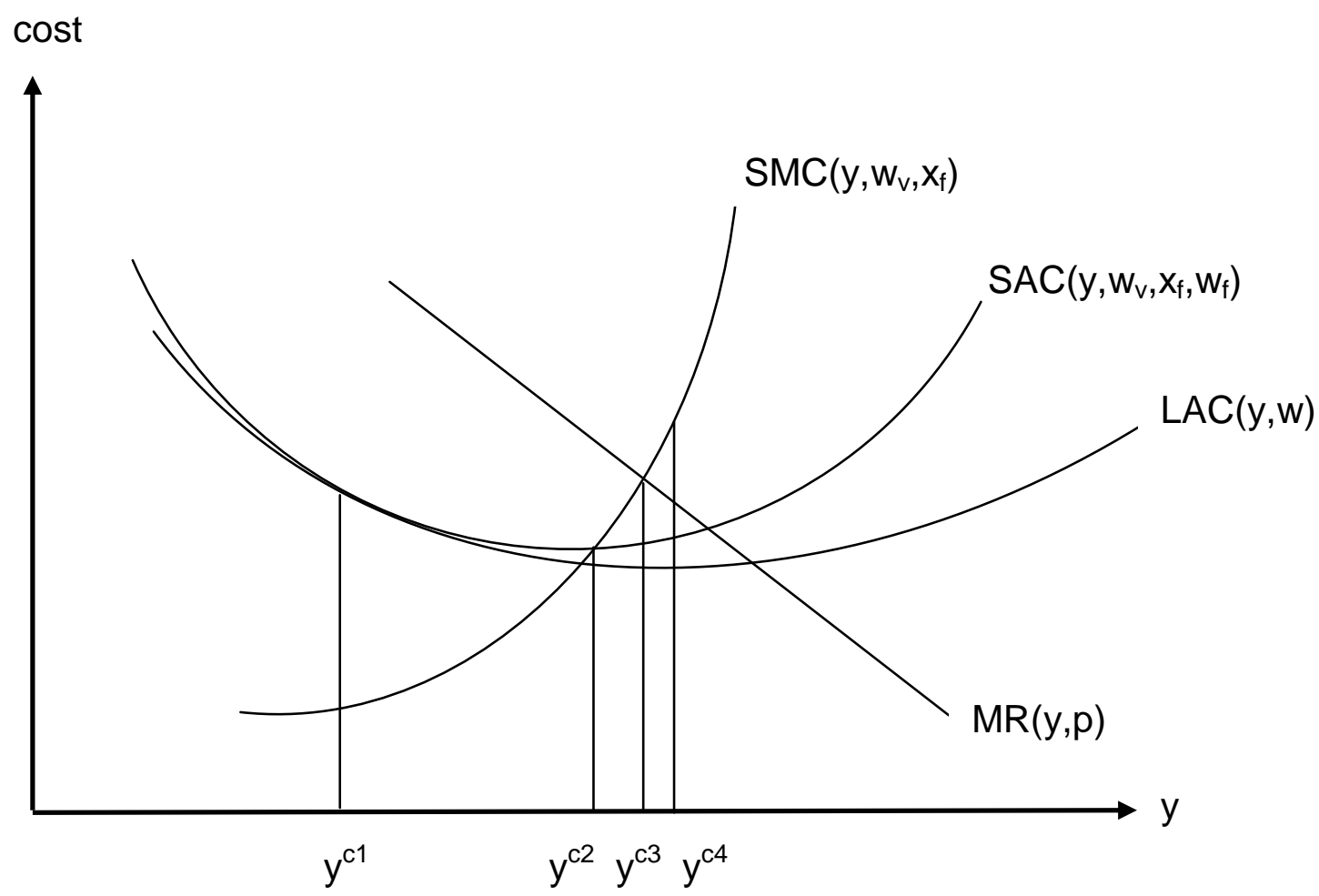

Figure 2 Input-oriented Capacity Utilization 


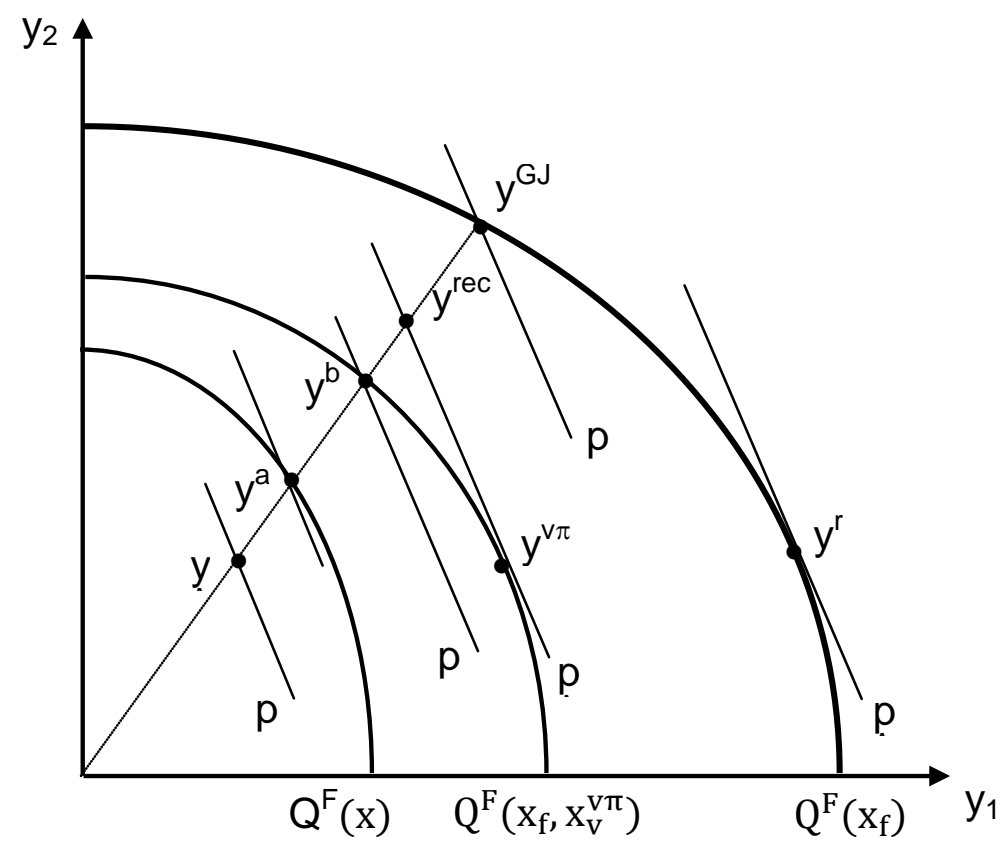

Figure 3 Output-oriented Capacity Utilization 


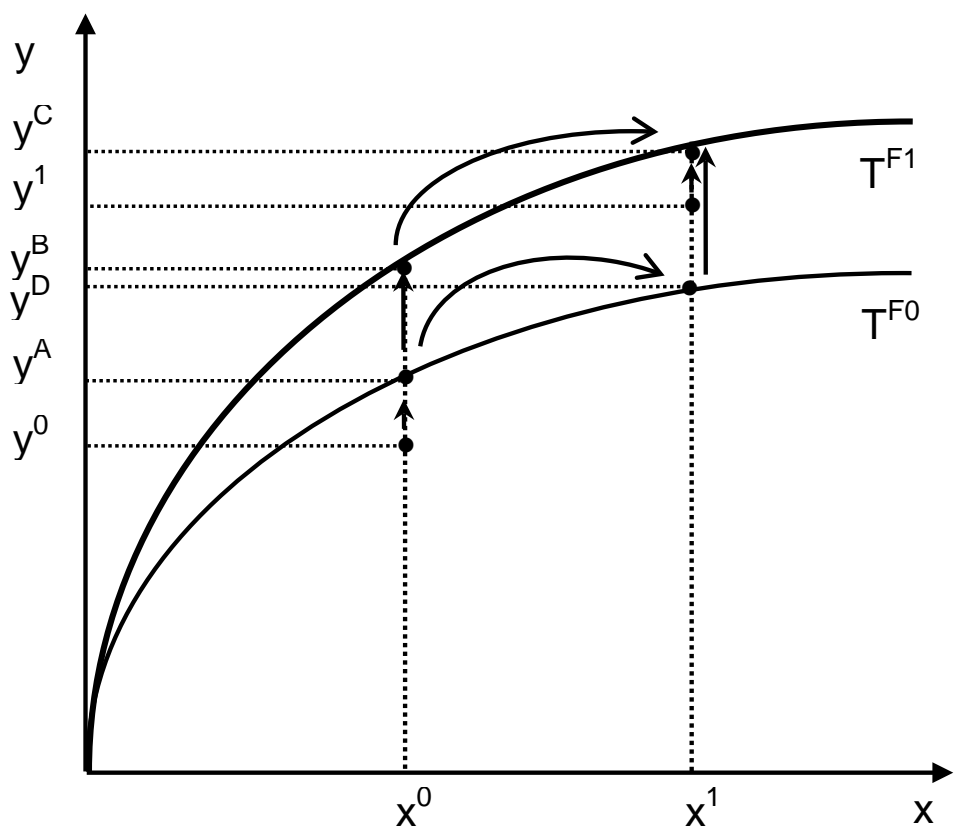

Figure 4 Output-oriented Productivity Effect Decomposition 


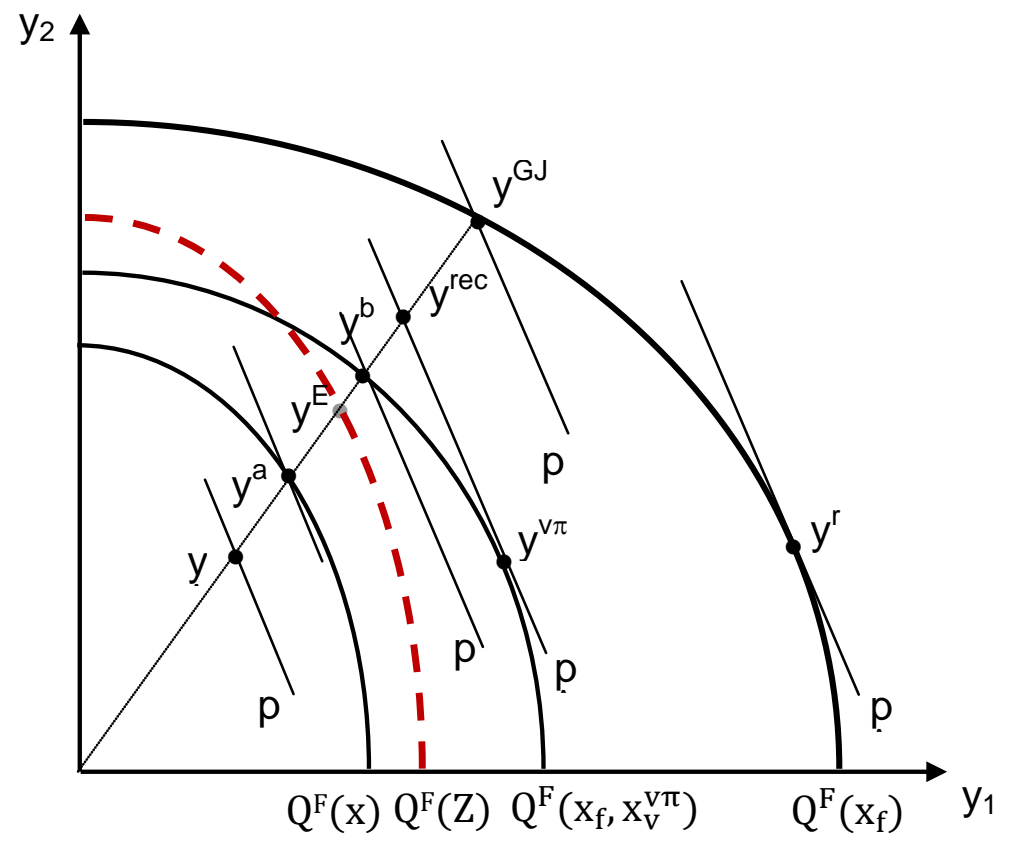

Figure 5 Internal and External Capacity Constraints 


\section{References}

ABARES (Australian Bureau of Agricultural and Resource Economics and Sciences) (2013), Australian Fisheries Surveys Report 2012. www.daff.gov.au/abares/publications_remote_content/publication_topics/fisheries_a nd_aquaculture

Balk, B. M. (2010), "An Assumption-free Framework for Measuring Productivity Change," Review of Income and Wealth 56:1 (June), S224-56.

Berndt, E. R., and C. J. Morrison (1981), "Capacity Utilization Measures: Underlying Economic Theory and an Alternative Approach," American Economic Review 71:2 (May), 48-52.

Bliss, J. H. (1923), Financial and Operating Ratios in Management. New York: The Ronald Press Co.

Caves, D. W., L. R. Christensen and W. E. Diewert (1982), "The Economic Theory of Index Numbers and the Measurement of Input, Output, and Productivity," Econometrica 50:6 (November), 1393-1414.

Chandler, A. D. (1962), Strategy and Structure: Chapters on the History of the Industrial Enterprise. Cambridge, MA: The MIT Press.

Coelli, T., E. Grifell-Tatjé and S. Perelman (2002), "Capacity Utilisation and Profitability: A Decomposition of Short-Run Profitability," International Journal of Production Economics 79:3 (October), 261-78.

Davis, H. S. (1955), Productivity Accounting. Philadelphia: University of Pennsylvania Press.

DeBorger, B., and K. Kerstens (2000), "The Malmquist Productivity Index and Plant Capacity Utilization," Scandinavian Journal of Economics 102:2 (June), 303-10.

Estache, A., and E. Grifell-Tatjé (2013), "How (un)even was the Distribution of the Impacts of Mali's Water Privatization across Stakeholders?" Journal of Development Studies 49:4 (April), 4483-99.

FAO (United Nations Food and Agriculture Organization) (2000), "Report of the Technical Consultation on the Measurement of Fishing Capacity," FAO Fisheries Report No. 615, Rome.

Färe, R., S. Grosskopf and J. Kirkley (2000), "Multi-Output Capacity Measures and their Relevance for Productivity," Bulletin of Economic Research 52:2 (April), 101-12.

Färe, R., S. Grosskopf and E. C. Kokkelenberg (1989), "Measuring Plant Capacity, Utilization and Technical Change: A Nonparametric Approach," International Economic Review 30:3 (August), 655-66.

Frankel, M. (1963), "Review of Kendrick \& Creamer (1961)," Journal of the American Statistical Association 58:301 (March), 258-59.

Gold, B. (1955), Foundations of Productivity Analysis. Pittsburgh, PA: University of Pittsburgh Press.

Grifell-Tatjé, E., and C. A. K. Lovell (1995), "A Note on the Malmquist Productivity Index," Economics Letters 47:2 (February), 169-75. 
Grifell-Tatjé, E., and C. A. K. Lovell (1999), "A Generalized Malmquist Productivity Index," Top 7:1, 81-101.

Grosskopf, S. K. J. Hayes, L. L. Taylor and W. L. Weber (1997), "BudgetConstrained Frontier Measures of Fiscal Equality and Efficiency in Schooling," Review of Economics \& Statistics 79:1 (February), 116-24.

Grosskopf, S. K. J. Hayes, L. L. Taylor and W. L. Weber (1999), "Anticipating the Consequences of School Reform: A New Use Of DEA," Management Science 45:4 (April), 608-20.

Hickman, B. G. (1964), "On a New Method of Capacity Estimation," Journal of the American Statistical Association 59:306 (June), 529-49.

Johansen, L. (1968), "Production Functions and the Concept of Capacity," in Recherches Récent sur la Function de Production. Collection Économie Mathématique et Économétrie 2, Centre d'Études et de la Recherche, Université de Namur, Belgium. [Reprinted in F. R. Førsund, ed., Collected Works of Leif Johansen, Vol 1. Amsterdam: North-Holland (1987)].

Johnson, H. T. (1972), "Early Cost Accounting for Internal Management Control: Lyman Mills in the 1850s," Business History Review 46:4 (Winter), 466-74.

Johnson, H. T. (1975), "Management Accounting in an Early Integrated Industrial: E. I. duPont de Nemours Powder Company, 1903-1912," Business History Review 49:2 (Summer), 184-204.

Johnson, H. T. (1978), "Management Accounting in an Early Multidivisional Organization: General Motors in the 1920s," Business History Review 52:4 (Winter), 490-517.

Kendrick, J. W., and D. Creamer (1961), Measuring Company Productivity: Handbook with Case Studies. Studies in Business Economics 74. New York: The Conference Board.

Kendrick, J. W., and E. S. Grossman (1980), Productivity in the United States: Trends and Cycles. Baltimore: Johns Hopkins University Press.

Klein, L. R. (1960), "Some Theoretical Issues in the Measurement of Capacity," Econometrica 28:2 (April), 272-86.

Kline, C. A. Jr., and H. L. Hessler (1952), "The du Pont Chart System for Appraising Operating Performance," N. A. C. A. Bulletin (August, Section 3), 1595-1619.

de Leeuw, F. (1962), "The Concept of Capacity," Journal of the American Statistical Association 57:300 (December), 826-40.

Lindebo, E., A. Hoff and N. Vestergaard (2007), "Revenue-based Capacity Utilisation Measures and Decomposition: The Case of Danish North Sea Trawlers," European Journal of Operational Research 180:1 (July), 215-27.

Machlup, F. (1952), The Economics of Sellers' Competition. Baltimore: The Johns Hopkins Press.

Malmquist, S. (1953), "Index Numbers and Indifference Surfaces," Trabajos de Estadistica 4, 209-42. 
Maxwell, W. D. (1965), "Short-Run Returns to Scale and the Production of Services," Southern Economic Journal 32:1 (July), 1-14.

Pincus, J., and H. Ergas (2008), "Improving the Efficiency of Australian Coal Chains," Report to the Queensland Competition Authority. www.qca.org.au

Ray, S. C., and E. Desli (1997), "Productivity Growth, Technical Progress, and Efficiency Change in Industrialized Countries: Comment," American Economic Review 87:5 (December), 1033-39.

Rodriguez-Álvarez, A., D. Roibás-Alonso and A. Wall (2012), "The Response of Decentralized Health Services to Demand Uncertainty and the Role of Political Parties in the Spanish Public Health System," Journal of Productivity Analysis in press.

Schultze, C. L. (1963), "Uses of Capacity Measures for Short-Run Economic Analysis," American Economic Review 53:2 (May), 293-308.

Segerson, K., and D. Squires (1990), "On the Measurement of Economic Capacity Utilization for Multi-Product Industries," Journal of Econometrics 44:3 (June), 347-61.

Segerson, K., and D. Squires (1995), "Measurement of Capacity Utilization for Revenue-Maximizing Firms," Bulletin of Economic Research 47:1 (January), 77-84.

Shephard, R. W. (1974), Indirect Production Functions. Mathematical Systems in Economics, No. 10. Meisenheim Am Glan, Germany: Verlag Anton Hain.

Shubik, M. (2011), "A Note on Accounting and Economic Theory: Past, Present and Future," Accounting, Economics, and Law 1:1 www.bepress.com/ael/vol1iss1/1

Smithies, A. (1957), "Economic Fluctuations and Growth," Econometrica 25:1 (January), 1-52.

Squires, D., R. Yongil Jeon, Q. Grafton and J. Kirkley (2010), "Controlling Excess Capacity in Common-Pool Resource Industries: The Transition from Input to Output Controls," Australian Journal of Agricultural and Resource Economics 54:3 (July), 361-77.

Walden, J. B., J. E. Kirkley, R. Färe and P. Logan (2012), "Productivity Change under an Individual Transferable Quota Management System," American Journal of Agricultural Economics 94:4 (July), 913-28.

Ward, J., P. Mace and E. Thunberg (2005), "The Relationship of Fish Harvesting Capacity to Excess Capacity and Overcapacity," Marine Resource Economics 19:4, 525-29. 
*This paper is an outgrowth of presentations at the National Marine Fisheries Service Productivity Workshop, Santa Cruz, CA, the Taiwan Productivity and Efficiency Conference, Taipei, and the VII North American Productivity Workshop, Rice University, Houston, TX, all in June and July, 2012. We thank our discussants, formal and informal, at each gathering. We also thank our referee for many productive insights. We express our gratitude to Lilyan Fulginiti for organizing the NAPW session in memory of Catherine Morrison Paul, who devoted much of her career to the study of productivity and capacity utilization, two topics we address, against a backdrop of mining and fisheries industries, in this paper, which we dedicate to the memory of Catherine Morrison Paul.

${ }^{1}$ Source: http://au.advfn.com.

${ }^{2}$ Chandler $(1962)$ and Johnson $(1975,1978)$ detail the development and use of the ROA triangle at duPont and GM.

${ }^{3}$ In a growth accounting context Balk (2010) defines the numerator of ROA as gross operating surplus, revenue minus the costs of labor and intermediate inputs (or equivalently value added less labor cost). This surplus, which Balk calls a return to the capital input, is called investor input by Davis (1955) and Kendrick \& Creamer (1961), and in principle has price (the rate of return to capital) and quantity (capital) components. Balk uses this framework, together with an assumed average rate of utilization of the productive capital stock, to both simplify and extend the analytical framework we develop in Section 4 . The extension involves the creation of a two-fold role for $\mathrm{CU}$ change. One role is as an independent driver of ROA change as in our expressions (15), (21) and (22); the other is as an adjustment factor that converts capital in existence to capital in use that corrects measures of productivity change.

${ }^{4}$ Klein proposed an entirely different tangency solution, one of Chamberlinian excess capacity brought on by imperfect competition. In this situation actual output at the tangency solution must fall short of capacity output at the minimum point on the short run average cost frontier, and so $\mathrm{CU}<1$.

${ }^{5}$ Segerson \& Squires $(1990,1995)$ consider primal and dual measures of capacity utilization for multiple-product firms that do not require the construction of an aggregate output quantity index. For the primal measure they consider two options: homothetic separability, so that $c(y, w)=h(y) g(w)$ and/or $c_{v}\left(y, w_{v}, x_{f}\right)=h_{v}(y) g_{v}\left(w_{v}, x_{f}\right)$, and a radial measure similar to those of Gold and Johansen that ignores a non-radial component of $\mathrm{CU}$ associated with differences in the output mixes in $y$ and $y^{c}$. For the dual measure they derive $\mathrm{CU}$ measures from the shadow value of a single fixed input. They also allow for multiple fixed inputs, and note that non-unitary ratios of shadow values to market prices generate non-unitary partial capacity utilization measures that can be offsetting and generate $\mathrm{CU}=1$.

${ }^{6}$ Without adopting our terminology, FAO (2000) has endorsed this physical measure of capacity utilization for use in fisheries, in part due to the shortage of reliable information on output and variable input prices that are required in subsequent definitions.

${ }^{7}$ Economically optimal idle capacity is analogous to what Rodriguez et al. (2012) call "...voluntary creation of excess service capacity...to deal with demand uncertainty..." by hospital managements.

${ }^{8}$ Following this line of reasoning would provide a new interpretation of the theory of cost indirect production pioneered by Shephard (1974) and extended by Färe et al. (2000), although it would introduce yet another component of the rate of capacity utilization. It is worth noting that our focus on capacity utilization inspires a fixed cost indirect approach, whereas an interest in "throwing money at schools" motivated Grosskopf et al. $(1997,1999)$ to develop a variable cost indirect approach. 
${ }^{9}$ Cost allocation may be an "open problem in economic theory and accounting," but Johnson (1972) describes in great detail its use for internal management control at a mid-nineteenth century American cotton textile mill.

${ }^{10}$ Grifell-Tatjé \& Lovell (1995) showed that the two components $\mathrm{D}_{\mathrm{o}}^{1}\left(\mathrm{x}^{1}, \mathrm{y}^{1}\right) / \mathrm{D}_{\mathrm{o}}^{0}\left(\mathrm{x}^{0}, \mathrm{y}^{0}\right)$ and $\mathrm{D}_{\mathrm{o}}^{0}\left(\mathrm{x}^{1}, \mathrm{y}^{1}\right) / \mathrm{D}_{0}^{1}\left(\mathrm{x}^{1}, \mathrm{y}^{1}\right)$ measure technical efficiency change and technical change. They asserted that "...the Malmquist productivity index does not accurately measure productivity change. The bias is systematic, and depends on the magnitude of scale economies." Our present effort to augment $\mathrm{M}_{\mathrm{o} C \mathrm{CD}}^{0}\left(\mathrm{x}^{1}, \mathrm{x}^{0}, \mathrm{y}^{1}, \mathrm{y}^{0}\right)$ with a size change effect has antecedents; Ray \& Desli (1997) and Grifell-Tatjé \& Lovell (1999) have augmented the CCD productivity index with a size change term, although these terms differ.

${ }^{11}$ It is, however, possible to combine the two approaches in expressions (15) and (17), giving $\mathrm{CU}$ change a two-fold role, as a component of asset turnover change and as an influence on productivity change, by inserting the right side of expression (3) into expression (15), although this approach may be accused of double counting the contribution of CU change to ROA change. Schultze went further still, suggesting that CU change also influences price change, and therefore the share of income going to profits, a distributional issue we do not pursue.

${ }^{12}$ The ROA change decomposition in expressions (21) and (23) is based on Laspeyres and Paasche price recovery and productivity indexes. It does not appear possible to generate a similar decomposition based on Edgeworth-Marshall arithmetic mean price recovery and productivity indexes because these ROA change decompositions derive from expression (6), which does not decompose using Edgeworth-Marshall price and quantity vectors because this introduces a third pair $(\overline{\mathrm{p}}, \overline{\mathrm{w}})$ and $(\overline{\mathrm{y}}, \overline{\mathrm{x}})$ into the analysis.

${ }^{13}$ Mining Australia reports that floods in 2011 reduced Queensland's coal exports by 20\%. http://www.miningaustralia.com.au/news/qld-flood-damage-confirmed. Pincus \& Ergas (2008) analyze Australian mining supply infrastructure bottlenecks, due largely to diffuse and uncoordinated ownership of port terminals, tracks and rolling stock. They cite a study commissioned by the Queensland government that estimated that revenues in excess of a billion AUD per year were sacrificed to inefficiencies in a single coal supply chain.

${ }^{14}$ The literature treats excess capacity as a short run problem that is a self-correcting phenomenon that fishery financial incentives eventually eliminate, and over-capacity as a long run problem resulting from market failure associated with the commons that can be solved only by creating fisher ownership rights. Ward et al. (2005) discuss both capacity concepts and appropriate management policies.

${ }^{15}$ Squires et al. (2010) and Walden et al. (2012) provide evidence on the capacity-reducing and distributional impacts of TAC and ITQ in the British Columbia halibut fishery and the mid-Atlantic surf-clam and ocean quahog fishery, respectively. These studies find evidence of reductions in over-capacity through exit of relatively unproductive vessels, entry of relatively productive vessels, and increases in average vessel size. 